\title{
El Museo de Arte Moderno de Bogotá entre 1962 y 1967. Apuntes para una historia de los museos de arte en Colombia
}

\author{
The Museum of Modern Art of Bogotá between 1962 and 1967. \\ Some notes for history of art museums in Colombia \\ O Museu de Arte Moderno de Bogotá entre 1962-1967. \\ Para uma história dos museus de arte em Colômbia
}

William Alfonso López Rosas

Instituto de Investigaciones Estéticas Universidad Nacional de Colombia, sede Bogotá walopezr@unal.edu.co

Fecha de presentación: 15 de enero de 2018

Fecha de aceptación: 24 de julio de 2018

Artículo de investigación 
RESUMEN

Este artículo hace una revisión crítica del Museo de Arte Moderno de Bogotá durante la administración de la artista Marta Traba. Con este propósito, la contribución hace una reinterpretación de una de las primeras narrativas institucionales sobre la trayectoria del museo, publicada en 1966 por Traba. La revisión de esta narrativa muestra la visión que la artista tenía tanto del proceso de institucionalización del museo, así como de sus propios posicionamientos críticos y sobre su ejercicio curatorial.

Palabras clave: historia del arte, historia cultural, historia latinoamericana, museología, Colombia, Marta Traba, arte moderno, Universidad Nacional de Colombia, siglo XX, campo cultural.

ABSTRACT

This article provides a critical review of the operation of the Museum of Modern Art of Bogotá during the administration of the artist Marta

Traba. With that in mind, it reinterprets one of the first institutional narratives on the evolution of this museum, published by Traba in 1966. The review of this narrative provides a critical approach to the vision that the artist had for both the process of providing

the museum with an institutional framework and the personal stances she took, as well as the curatorial duties that she performed.

Keywords: Art history, cultural history, Latin American history, museology, Colombia, Marta Traba, modern art, National University of Colombia, twentieth century, cultural sector

RESUMO

O artigo faz uma revisão crítica do Museu de Arte Moderno de Bogotá durante a administração da artista plástica Marta Traba. Com esse alvo, oferece-se uma reinterpretação de um do primeiros relatos institucionais, publicado por Traba em 1966, sobre trajeto do museu. A revisão desse relato oficial mostra criticamente a visão da artista sobre o processo de institucionalização d o museu, os posicionamentos que adotou, além do seu próprio exercício curatorial.

Palavras chave: História da arte, história cultural, história da América Latina, museologia, Colômbia, Marta Traba, arte moderno, Universidade Nacional de Colômbia, século XX, campo cultural. 


\section{INTRODUCCIÓN}

En otro lugar se ha afirmado que la historia de los museos de arte en Colombia es un terreno completamente inexplorado, no solo porque los procesos de instauración y consolidación de la historia del arte como disciplina es muy incipiente en el país, sino porque, en concomitancia con esta situación, sus objetos de estudio se han reducido en términos generales al análisis, desde una perspectiva modernista, de las obras de arte y la trayectoria de los artistas. En este contexto, dentro de la producción histórico-artística en Colombia, como eventualmente ocurrió hasta hace más o menos una década, con relación a la historia de la crítica de arte, la historiografía académicamente enunciada carece de hipótesis interpretativas y relatos críticos de largo aliento sobre las dinámicas de anclaje de las instituciones museales dentro del campo artístico; y, en este sentido, ni los especialistas ni el público aficionado han podido construir un imaginario sobre su papel en el seno de los procesos de administración de la consagración artística; es decir, dentro de la construcción del canon artístico, y, en consecuencia, dentro de la configuración y agenciamiento de discursos historiográficos con vocación hegemónica, en su relación con el mercado del arte en particular, y, más allá, en su articulación con las dinámicas de perpetuación de los procesos de dominación que las élites políticas en Colombia han monopolizado con singular eficacia. ${ }^{1}$

Si bien es cierto que, gracias a la creación y desarrollo de algunos programas de posgrado, ${ }^{2}$ la historia del arte en las últimas décadas en Colombia

1. Véase William Alfonso López Rosas, "Apuntes para una historia del Museo de Arte Moderno de Bogotá: la autonomización del campo cultural y la construcción de la hegemonía del arte modernista (1949-1970)", Cuadernos de Música, Artes Visuales y Artes Escénicas 10, n. ${ }^{\circ}$ (julio-diciembre 2015): 15-35.

2. Es posible que el origen de la formación profesional en el ámbito de la historia del arte y la gestión del patrimonio cultural en Colombia se pueda remontar hasta el final de la década de los años setenta del pasado siglo, cuando se funda, en 1978, el Instituto de Investigaciones Estéticas en la Universidad Nacional de Colombia; sin embargo, es con la creación de la Maestría en Historia y Teoría del Arte, la Arquitectura y la Ciudad, en 1989, en esta misma casa de estudios, cuando arranca definitivamente el proceso de diferenciación académica de la disciplina. Durante más de veinte años, este será el único programa que formará los primeros historiadores del arte en Colombia, hasta la aparición, en otras instituciones (Universidad de Antioquia, Universidad de los Andes, Fundación Universidad de Bogotá Jorge Tadeo Lozano), de otros programas de posgrado que, con algunas diferencias, fortalecerán paulatinamente los procesos de profesionalización de la disciplina, pero sobre todo instalarán la producción historiográfica en lugares de enunciación diferentes a los departamentos de curaduría de los museos de arte. Este proceso se remata, a mediados de la primera década del siglo XXI, con la aparición en la Universidad de los Andes y en la 
ha ampliado tanto los temas de investigación como las miradas teóricas y metodológicas de sus indagaciones, el museo continúa siendo un objeto de estudio eludido. Ni se lo comprende dentro de la densidad teórica que ha configurado la museología contemporánea, ni se le referencia como pieza clave de la trama histórica que configura socialmente tanto a los artistas como a sus obras o prácticas. Con muy contadas excepciones, ${ }^{3}$ la bibliografía sobre museos se reduce, entonces, a la narración burocrática de los hitos de sus trayectorias institucionales, ${ }^{4} \mathrm{O}$ a algunos artículos o tesis de pregrado y posgrado que replican sin ninguna distancia crítica esas crónicas; se trata de una producción que ni documenta de forma amplia y detallada las trayectorias de los museos de arte en el país, ni da cuenta de su propio aparataje teórico y metodológico. ${ }^{5}$ Así que ni por intención ni por complejidad, esta producción

Fundación Universidad Jorge Tadeo Lozano de los dos primeros pregrados en Historia del Arte en Colombia, que auguran la institucionalización definitiva de la disciplina.

3. Acaso los trabajos de Alessandro Armatto e Isabel Cristina Ramírez sobre los museos de Cartagena y Barranquilla constituyan una gran excepción a la regla planteada. Los datos bibliográficos de sus trabajos puntales sobre este tema son: Alessandro Armatto, "La 'primera piedra': José Gómez Sicre y la fundación de los museos interamericanos de arte moderno de Cartagena y Barranquilla", Revista Brasileira do Caribe 12, n. 24 (enero-junio 2012): 381-404; Isabel Cristina Ramírez Botero, El arte en Cartagena a través de la colección del Banco de la República (Cartagena: Banco de la República, 2010).

4. Sin buscar la exhaustividad absoluta, los lectores y lectoras interesados pueden consultar un variado conjunto de relatos institucionales enunciados por los mismos museos, así: Eduardo Serrano, El Museo de Arte Moderno de Bogotá. Recuento de un esfuerzo conjunto (Bogotá: Museo de Arte Moderno de Bogotá, 1979); Ángela Mejía de López, La escultura en la Colección Pizano (Bogotá: Museo de Arte / Universidad Nacional de Colombia, 1984); Gloria Zea, El Museo de Arte Moderno de Bogotá. Una experiencia singular (Bogotá: Museo de Arte Moderno de Bogotá / El Sello Editorial, 1994); Maritza Uribe de Urdinola y Miguel González, Museo de Arte Moderno La Tertulia (Cali: Museo de Arte Moderno La Tertulia, 1996); Marta Rodríguez, La abstracción en Colombia vista desde la colección del Museo de Arte de la Universidad Nacional-Obra bidimensional (Bogotá: Museo de Arte / Universidad Nacional de Colombia, 1998); Marta Rodríguez, El dibujo en Colombia. Una mirada a la colección del Museo de Arte de la Universidad Nacional de Colombia (Bogotá: Museo de Arte / Universidad Nacional de Colombia, 2001); Santiago Londoño Vélez, Arte colombiano 3.500 años de historia. Colección Banco de la República (Bogotá: Villegas Editores, 2001); VV. AA., La contemporaneidad en Colombia-Museo de Arte Contemporáneo 40 años (Bogotá: Museo de Arte Contemporáneo / Corporación Universitaria UNIMINUTO, 2006); VV. AA., Museo de Arte Moderno de Cartagena de Indias (Cartagena: Asociación de Amigos del Museo de Arte Moderno de Cartagena de Indias / Villegas Editores, 2009); Beatriz González, Arte internacional. Colección del Banco de la República (Bogotá: Villegas Editores, 2009).

5. Los artículos y tesis referidos son: María del Carmen Suescún Pozas, "Los museos de arte moderno y la reconfiguración de lo local a través de lo foráneo: transformando a Colombia en un país 'abierto' ", Memoria y Sociedad 3, n. 6 (1999): 135-142; Julián Andrés González Gallego, "El Museo La Tertulia: 50 años de frente a la ciudad” (tesis de la Universidad del Valle, Cali, 2006); María del Pilar Quintero Montero, “El Museo de Arte Mo- 
ha logrado configurar hipótesis dentro de un arco histórico al menos de mediana duración, desde las cuales se pueda articular una representación crítica de su incidencia en la instauración, configuración y apropiación social de la obra de arte. ${ }^{6}$

Pero lo que es más grave aún es que, más allá de las líneas escritas con fines divulgativos o mercadológicos, los museos de arte colombianos carecen de relatos que les permitan observar con perspectivas críticas la inserción funcional de su propio proyecto institucional dentro de la perpetuación de una institucionalidad cultural letrada de carácter oligárquico, que blinda en el ámbito cultural, el dominio detentado por ciertos grupos sociales particulares tanto en las regiones y como en el nivel nacional. Su tácita o explícita connivencia con las diversas dinámicas de exclusión simbólica y material de los grupos subalternos, y de censura y olvido de la obra de aquellos artistas que configuraron su trayectoria profesional en abierta contradicción ideológica o poética frente a los grupos dominantes dentro del campo artístico o, más allá, dentro del campo político o religioso, nunca ha sido conceptualizada y mucho menos estudiada, aunque sí episódicamente señalada. ${ }^{7}$

Por último, es importante señalar que los cuestionamientos que han sufrido estas instituciones en los últimos tiempos bajo el influjo de la emergente crítica institucional, han sido planteados desde marcos conceptuales abstractos y, por lo general, anacrónicos, desconociendo de forma absoluta la trayectoria histórica de sus proyectos museológicos, y, por tanto, la propia densidad de los capitales axiológicos en juego, pero, sobre todo, las relaciones de poder que han permitido su instauración y acción dentro del campo cultural. ${ }^{8}$ Así, las duras críticas dirigidas contra la administración de sus co-

derno de Bogotá: formación y programa cultural entre 1963 y 1965. Trabajando por crear un espacio para el arte moderno" (tesis de maestría, Universidad de Bogotá Jorge Tadeo Lozano, 2015); Alexandra Mesa Mendieta, "Museo de Arte Moderno de Bogotá: Primera pincelada 1963-1965", Quintana, n. ${ }^{\circ} 15$ (2016): 203-222.

6. López Rosas, "Apuntes para una historia...", 18.

7. Sin duda, por el lugar que ocupa el Museo Nacional de Colombia dentro de la institucionalidad cultural colombiana, pero también por ser una de las pocas organizaciones museológicas que el Estado nacional ha apoyado de forma más o menos regular, este ha sido objeto de varias críticas, referidas casi todas al papel que esta cumple dentro de las dinámicas de representación de la nación. Véase Gonzalo Sánchez Gómez y María Emma Wills Obregón, Museo, memoria y nación. Misión de los museos nacionales para los ciudadanos del futuro. Memorias del Simposio Internacional y del IV Cátedra Anual de Historia Ernesto Restrepo Tirado (Bogotá: Museo Nacional de Colombia, 1999); y, La arqueología, la etnografía, la historia y el arte en el Museo. Memorias de los coloquios nacionales, ed. por Marta Segura (Bogotá: Museo Nacional de Colombia, 2001).

8. Tal vez el debate que suscitó la exposición Moda Latinoamericana Barbie, realizada por el Museo de Arte Moderno de Bogotá, en el primer semestre de 2003, es uno de los más elocuentes de todos los que se han presentado en las últimas décadas en el medio cultural 
lecciones, la programación de sus espacios expositivos y, sobre todo, contra la monopolización de su dirección por parte de agentes particulares, y, en consecuencia, contra la inmovilidad y torpeza subsecuente de su gestión administrativa, hacen caso omiso de las circunstancias históricas y sociales particulares dentro de las cuales se han configurado sus proyectos institucionales, autoneutralizando la posibilidad de una transformación radical de las situaciones señaladas.

En este texto, en el marco de una investigación histórica que se pregunta por la función que desempeñó del Museo de Arte Moderno de Bogotá dentro del proceso de autonomización del campo cultural colombiano, ${ }^{9}$ se presentará una lectura crítica de uno de los textos fundacionales de la narrativa "oficial" que esta institución ha promovido sobre su propia trayectoria institucional, con el ánimo de dar un primer paso hacia la construcción de un relato crítico sobre el papel que esta organización cultural desempeñó dentro de la configuración de la hegemonía del modernismo plástico dentro del subcampo artístico colombiano, desde principios de la década de los sesenta. Desde la perspectiva de la sociología de la cultura esbozada por Pierre Bourdieu, ${ }^{10}$ interesa dilucidar el lugar que el Museo de Arte Moderno de Bogotá ocupó dentro de dos procesos que corren paralelos y en imbricada relación a lo largo de los años sesenta y setenta: la institucionalización del modernismo plástico en la escena artística y la consolidación en clave letrada del proceso de autonomización del campo cultural colombiano.

En discusión con la modesta pero muy fecunda serie de trabajos que en los últimos años se han producido en Colombia sobre la configuración del campo intelectual, ${ }^{11}$ precisamente en diálogo con la perspectiva de la sociología de la

colombiano. Publicado originalmente en el sitio virtual http: / / esferapublica.org, trascendió el medio estrictamente artístico y llegó a las páginas de algunos de los periódicos y revistas de circulación masiva. Véase William Alfonso López Rosas, "Museos, patrimonio cultural y mecenazgo: los límites conceptuales de la financiación de las instituciones de la memoria en Colombia", Revista Colombiana de Antropología 46, n. ${ }^{\circ} 1$ (enero-junio 2010): 87-114.

9. Aquí se hace referencia al proyecto de investigación doctoral titulado "Arte, museo y autonomización del campo cultural en Colombia: el Museo de Arte Moderno de Bogotá y la construcción de la hegemonía del arte modernista (1949-1970)", dentro del programa de doctorado en Arte y Arquitectura de la Universidad Nacional de Colombia (2010).

10. Véase principalmente Pierre Bourdieu, Las reglas del arte. Génesis y estructura del campo literario (Barcelona: Anagrama, 1995).

11. Véase Ruth Nohemí Acuña Prieto, "El papel periódico ilustrado y la génesis de la configuración del campo artístico en Colombia" (tesis de maestría, Universidad Nacional de Colombia, sede Bogotá, 2002); Alejandro Garay Celeita, "El campo artístico colombiano en el Salón de 1910", Historia Crítica, n. 32 (julio-diciembre, 2006): 302-333; Carmen María Jaramillo Jiménez, "Una mirada a los orígenes del campo de la crítica de arte en Colombia", Artes. La Revista 4, n. 7 (2004): 3-38; Jaime Eduardo Jaramillo Jiménez, "Protocampo y campo intelectual en Latinoamérica: los intelectuales en la periferia" (inédito, 2003); Universidad, 
cultura configurada por Bourdieu, se desarrollará la lectura del texto titulado Museo de Arte Moderno de Bogotá, publicado en 1966, en la forma de dossier promocional de las actividades de esta institución, con la tácita autoría de Marta Traba (1923-1983), quien para ese momento se desempeñaba como su directora.

El criterio de lectura e interpretación que se pondrá en funcionamiento está fundado en la descripción sucinta de la posición que ocupaba Traba en el momento de su enunciación dentro del subcampo artístico colombiano, es decir, del cruce entre a) una caracterización concisa de su habitus, b) la descripción puntual de su trayectoria profesional, y por último c) la reseña de sus planteamientos. Se busca, desde esta perspectiva, construir una descripción mínima del estado del subcampo artístico con el fin de ubicar la posición particular de Traba dentro de las luchas por el monopolio de las instancias de legitimación artística, para, desde allí, interpretar el sentido general de sus afirmaciones.

Aunque este no es el lugar para extenderse sobre el sentido que Bourdieu da a los conceptos de posición, trayectoria y habitus, sí es necesario puntualizar que este análisis busca hacer visibles, así sea de forma parcial, las relaciones de poder implícitas en el acto de enunciación del documento analizado, que dichas categorías permiten vislumbrar. ${ }^{12}$ En este sentido, se trata de hacer

politica y cultura: la rectoría de Gerardo Molina en la Universidad Nacional de Colombia, 1944-1948 (Bogotá: Universidad Nacional de Colombia, 2007); William Alfonso López Rosas, "La crítica de arte en el Salón de 1899: una aproximación a los procesos de configuración del campo artístico en Colombia" (tesis de maestría, Universidad Nacional de Colombia, sede Bogotá, 2005); Miguel Ángel Urrego, Intelectuales, Estado y nación en Colombia. De la guerra de los Mil Días a la Constitución de 1991 (Bogotá: Siglo del Hombre / Universidad Central, 2002).

12. Según Luc Boltanski y Alicia B. Gutiérrez, la noción de habitus es introducida por Bourdieu en el ámbito de sus reflexiones teóricas hacia 1968, en el contexto inicial de sus investigaciones sobre la escuela. Desde la perspectiva de Bourdieu, el habitus remite a las condiciones sociales que configuran a los agentes como sujetos sociales (familia, etc.), y como productores (escuela, contactos profesionales, etc.), y, por otro lado, a la posición que ocupan en un campo de poder determinado, a través de las demandas y limitaciones sociales que los circunscriben dentro de un espacio social particular. Bourdieu afirma: “Lo que se llama 'creación' es la confluencia de un habitus socialmente constituido y una determinada posición ya instituida o posible en la división del trabajo de producción cultural (y, además de todo, en segundo grado, en la división del trabajo de dominación); el trabajo con el cual el artista hace su obra y, de manera inseparable, se hace a sí mismo como artista (y, cuando ello forma parte de la demanda del campo, como artista original, singular) puede describirse como la relación dialéctica entre su puesto, que a menudo lo precede y lo sobrevive (por ejemplo, con las obligaciones de la 'vida de artista', ciertos atributos, tradicionales, formas de expresarse [...]) y su habitus que lo hace más o menos propenso a ocupar este puesto o transformarlo de manera más o menos completa -lo cual puede ser uno de los prerrequisitos del puesto-. En suma, el habitus del productor no es nunca totalmente el producto del puesto (salvo quizá en ciertas tradiciones artesanales donde la formación familiar, es decir, los condicionamientos sociales originales de clase, y 
explícitos los argumentos a través de los cuales Traba justificó su acción dentro y desde el Museo de Arte Moderno de Bogotá, en el marco del proceso histórico de instauración del principio de legítima legitimación propio de las luchas de dominación en los campos de poder, ${ }^{13} \mathrm{y}$, en concomitancia, dentro del proceso de monopolización de las tareas de consagración artística. Se busca dilucidar, a través del análisis histórico-crítico, la forma cómo Traba participó dentro de las disputas por el monopolio del privilegio de determinar qué producciones y qué artistas eran dignos de ser escenificados en la esfera pública letrada, lugar fundamental de constitución del valor tanto simbólico como económico de los artefactos estéticos que se presentaron y representaron como "obras de arte" en el espacio social directamente vinculado al campo artístico en el medio colombiano en el período mencionado.

Como correlato de este análisis, también se esbozarán los mecanismos de exclusión simbólica y material que eventualmente operaron con férrea eficacia para ocluir las trayectorias profesionales de los artistas que no se acomodaron a los valores impuestos por los agentes triunfantes dentro de las luchas de dominación del campo cultural, dentro de la producción historiográfica colombiana de los años setenta.

Se trata, en últimas, de comenzar a situar dentro del foco del análisis histórico-crítico el proceso institucional a través del cual determinados agentes monopolizaron la tarea de administrar la canonización artística, y, más allá, la de instaurar una gramática narrativa hegemónica dentro de la memoria y el imaginario letrados, en el período que va de mediados de los años cincuenta hasta el final de los años setenta en Colombia, dentro de un proceso que desarrolló de forma orgánica la política cultural del Estado nacional durante el llamado Frente Nacional (1958-1974).

\section{BREVÍSIMO PANORAMA HISTORIOGRÁFICO: CRÍTICA DE LA DEFINICIÓN MODERNISTA DE LA MODERNIDAD CULTURAL}

Para quien esté familiarizado con la historiografía del arte en Colombia, a estas alturas ya será clara la tarea que se está proponiendo: configurar una historia de los museos de arte desde una crítica a la noción de modernidad

la formación profesional se confunden por completo). De manera inversa, nunca se puede pasar directamente de las características sociales del productor -su origen social- a las características de su producto: las disposiciones vinculadas con un origen social determinado - plebeyo o burgués- pueden expresarse de maneras muy diferentes, al tiempo que conservan un aire familiar, en diferentes campos". Pierre Bourdieu, Sociología y cultura (México D. F.: Grijalbo / Consejo Nacional para la Cultura y las Artes, 1990), 228.

13. Véase Pierre Bourdieu, Meditaciones pascalianas (Barcelona: Anagrama, 1999), 136. 


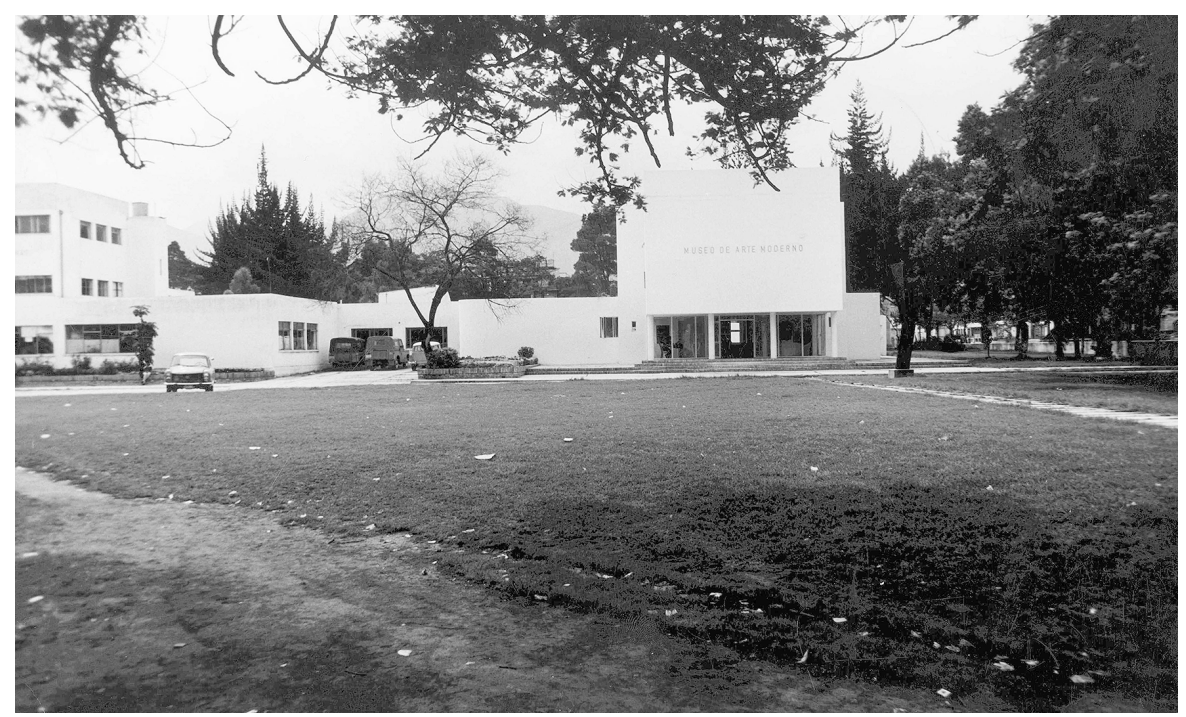

Figura 1. Fachada del Museo de Arte Moderno de Bogotá en el campus de la Universidad Nacional de Colombia. Foto: EGAR. En Marta Traba, Museo de Arte Moderno de Bogotá (Bogotá: Universidad Nacional de Colombia, 1966).

que la historiografía modernista, enunciada principalmente desde los museos de arte moderno colombianos, promovió desde principios de los años setenta. En otros términos: configurar una mirada histórica de largo aliento sobre las instituciones museológicas "modernas", a partir de la construcción de una distancia crítica frente a la noción de modernidad que esta tradición definió a partir de la ecuación unidimensional con la ideología del modernismo plástico que los museos de arte moderno legitimaron de forma sistemática a través de su acción expositiva, pero principalmente a través de una producción historiográfica, en muchos sentidos, funcional al mercado del arte.

En franca polémica con la concepción de la modernidad artística que esta tradición histórico-artística construyó desde mediados de los años cincuenta en Colombia, se busca problematizar los procesos de canonización cultural que se institucionalizaron durante la década de los setenta, a través, entre otros factores, de la publicación de obras como Historia abierta del arte colombiano (1974) de la misma Marta Traba; Historia del arte colombiano (1975), la extensa obra dirigida por Eugenio Barney-Cabrera (1917-1981) para la editorial Salvat;, ${ }^{14}$ pero sobre todo a través la consolidación de los museos de arte

14. Es imposible no mencionar aquí Procesos del arte en Colombia (1978) de Álvaro Medina (1941). Aunque este trabajo se puede inscribir dentro del paradigma historiográfico 
moderno, ${ }^{15}$ y de la instauración de la primera exposición permanente que explícitamente buscaba narrar la historia del arte colombiano en las salas del Museo Nacional de Colombia, cuando Emma Araújo de Vallejo (1930), ${ }^{16}$ una de las alumnas y amigas más cercanas de Traba, dirigió esta institución en el período que va de 1974 a 1982.

Con sus diferencias teóricas e ideológicas particulares -y aquí va la principal hipótesis de fondo-, estas historias, sumadas al denso número de exposiciones que se realizaron en las principales instituciones museales colombianas en ese período, y a la muestra permanente que pusieron en escena Araújo de Vallejo y los historiadores del arte que ella llamó en su auxilio, ${ }^{17}$ finalmente consolidaron las nociones de arte y artista puros, como el principal eje de construcción social de la obra de arte en el ámbito colombiano, blindando el dominio de las políticas de representación modernistas de la memoria histórica de las artes plásticas dentro del campo artístico, que Traba contribuyó a instaurar a lo largo de la década de los sesenta desde la dirección del Museo de Arte Moderno de Bogotá.

Para decirlo en otros términos, el principal objeto disciplinario que estas historias y las exposiciones de marras situaron en la esfera pública letrada, se instauró hegemónicamente a partir del paradigma ideológico modernista;

modernista que se describirá más adelante, por su lugar de enunciación pero también por la perspectiva sociológica desde la cual fue elaborado, se sitúa en una posición problemática, que ya empieza a prefigurar las monografías histórico-artísticas que empezarán a escribirse desde la academia universitaria al final de los años noventa.

15. La emergencia de los museos de arte moderno en Colombia, como ocurre en otros países latinoamericanos, se presentan desde mediados de la década de los cincuenta del siglo XX. La primera fundación del Museo de Arte Moderno de Bogotá data de 1955, a la que debe sumarse la creación, en 1956, del Museo de Arte Moderno La Tertulia, en Cali; la génesis de la colección de Arte del Banco de la República de Colombia, en 1957; la primera fundación del Museo de Arte Moderno de Cartagena, en 1959, la conformación del Museo de Arte Contemporáneo de Bogotá, en 1966; y la del Museo de Arte de la Universidad Nacional de Colombia, también en Bogotá, en 1970.

16. Emma Araújo de Vallejo es más conocida en América Latina por ser la directora general de la más compleja y extensa antología de la obra crítica de Marta Traba, publicada por el Museo de Arte Moderno de Bogotá y Planeta, en Bogotá, en 1984.

17. Con el fin de estudiar las colecciones del Museo Nacional de Colombia y de diseñar una nueva exposición permanente, en 1974, Emma Araújo de Vallejo, unos pocos meses después de ser nombrada como directora de esta institución, conformó dos grupos de trabajo: dentro de la comisión de artes plásticas convocó a los historiadores del arte Francisco Gil Tovar, Eugenio Barney-Cabrera, al curador Eduardo Serrano y a los artistas Luis Alberto Acuña y Beatriz González; dentro de la comisión de historia, ella convocó a Pilar Moreno de Ángel, Gabriel Giraldo Jaramillo, Eduardo Santa, Horacio Rodríguez Plata, José María de Mier, Alberto Lee López, Guillermo Hernández de Alba y Jaime Durán Pombo. Véase William Alfonso López Rosas, Emma Araújo de Vallejo. Su trabajo por el arte, la memoria, la educación y los museos (Bogotá: Universidad Nacional de Colombia, 2015). 
paradigma que, en Colombia, se configuró con la historización museológica de las vicisitudes biográfico-poéticas de los artistas modernistas, dentro de las cuales el creador se enfrenta, en una lucha mesiánica, con los demonios propios de la "mediocridad" y del "conservadurismo" del verismo académico, con el arduo trabajo de apropiación solitaria de las "verdades estéticas" pronunciadas por los grandes héroes de las primeras vanguardias europeas, y con el martirologio de la creación de un lenguaje propio, fruto del ejercicio profundo y sustancial de la libertad de su imaginación.

Si se quisiera caracterizar de forma somera, atendiendo de todos modos a las diferencias específicas de cada uno de los proyectos antes citados, se podría afirmar que los supuestos ideológicos de esta historiografía responde a las siguientes acciones conceptuales:

- Entronización de la subjetividad del artista, a través del regreso a la idea renacentista del genio creador.

- Endiosamiento romántico de la libertad de la imaginación del artista, y, en consecuencia, hipóstasis de la voluntad artística.

- Instauración de una estética pura basada en el proyecto poético del artista, como eje sustancial de valoración crítica de la producción artística y de construcción del discurso histórico.

- Ruptura ficticia de los vasos comunicantes entre la generación americanista y la generación modernista.

- Monopolización de la condición moderna a favor de los artistas que se acomodan a esta poética general, a través del uso crítico y no histórico de la definición de la modernidad.

- Reducción de los objetos de estudio de la historia del arte a la poética de los artistas y, en consecuencia, del concepto de modernización del arte a la paulatina apropiación, dentro de los proyectos poéticos de los artistas, de las estéticas de las vanguardias europeas, como único eje narrativo de la historia del arte.

En consecuencia, esta historiografía ha reducido el objeto de análisis disciplinario al proyecto poético del artista puro, usando el concepto de modernidad dentro de un ámbito ideológico que neutraliza su capacidad de caracterización histórica, resignificándolo como una categoría estética para el uso de la crítica de arte. La monopolización del concepto de modernidad que está en la base de la institucionalización del museo de arte moderno, ${ }^{18}$ se desarrolló en el ámbito colombiano dentro del lenguaje de la crítica y la historia del arte como una herramienta de legitimación y deslegitimación cultural, canonizando a un número muy reducido de autores y condenando una

18. Véanse Carol Duncan, Rituales de civilización (Murcia: Nausícaä, 2007) y Serge Guilbaut, De cómo Nueva York se robó la idea de arte moderno (Madrid: Mondadori, 1990). 
enorme producción cultural, en los casos más amables, a una domesticada e ingenua protomodernidad o, en los casos más pugnaces, a la más conservadora de las antimodernidades. El mito del creador increado y el imaginario propio de los procesos creativos ligados a la originalidad de la subjetividad, están en la base de esta definición unidimensional de la modernidad artística, que le niega el carácter moderno a todo aquello que pueda poner en peligro su autocomprensión, en particular las relaciones de poder que hacen posible la instauración pública del resultado del trabajo artístico como obra de arte. En consecuencia, al acaparar para sí el carácter moderno y negar de plano la modernidad a otros momentos históricos y otros objetos culturales, además de fundar con solidez la legitimidad de su dominio cultural, impide analizar otras prácticas artísticas e instituciones culturales fuera de los estrechos límites definidos por su autointerpretación de la modernidad misma. ${ }^{19}$

En contraste con esta historiografía, una historia del arte que se pregunte por las relaciones de poder que hacen posible la obra de arte como objeto cultural, así como los discursos críticos y las instituciones artísticas como realidades sociales, necesariamente tiene que construirse sobre una crítica a la historia modernista del arte modernista que se instaló como sentido común no solo de las políticas de coleccionismo de los museos de arte públicos y privados, sino de la acción general del Estado colombiano con respecto al sector de las artes plásticas y visuales.

En este contexto, la noción de autonomización de los campos de poder esbozada por Bourdieu, no solo permite establecer un espacio de análisis para dilucidar la posición de los sujetos de la enunciación de estas historias dentro del complejo proceso de lucha por el control de las narrativas historiográficas hegemónicas, sino, incluso, la redefinición de los objetos mismos de la historia del arte como disciplina. A partir de ella, pueden caracterizarse como objetos del análisis desde los supuestos a partir de los cuales se estableció la periodización de los procesos de modernización cultural, pasando por las efectos de poder que establecieron el canon artístico, así como la asunción pública de los agentes carismáticos protagónicos, y, particularmente, la instauración de nociones del gusto con base en las cuales se construyeron las colecciones públicas de arte.

En este punto vale la pena volver, así sea brevemente, sobre el concepto que Pierre Bourdieu tiene del proceso de autonomización de los campos de poder. Se trata, desde su perspectiva, de la dinámica a través de la cual un espacio social particular va liberándose de la injerencia directa de poderes ajenos a la propia producción simbólica y material de su especificidad "académica", "dis-

19. Véase William Alfonso López Rosas, “Miguel Díaz Vargas: una modernidad invisible". En Taller Historia Crítica del Arte Miguel Díaz Vargas: una modernidad invisible (Bogotá: Fundación Gilberto Alzate Avendaño, 2007), 19. 
ciplinaria" o profesional, a partir de la configuración histórica de un capital específico, a nombre del cual actúan los agentes inscritos en él. Bourdieu afirma:

El grado de autonomía del campo (y, con ello, el estado de las relaciones de fuerzas que en él se instauran) varía considerablemente según las épocas y las tradiciones nacionales. Depende del capital simbólico que se ha ido acumulando a lo largo del tiempo a través de la acción de las generaciones sucesivas (valor otorgado al nombre de escritor o de filósofo, licencia estatutaria y casi institucionalizada para poner en tela de juicio los poderes, etc.). En el nombre de este capital colectivo los productores culturales se sienten con el derecho o con la obligación de ignorar las demandas o las exigencias de los poderes temporales, incluso de combatirlas invocando en su contra sus principios y sus normas propias: cuando están inscritas en estado de potencialidad objetiva, o incluso de exigencia, en la razón específica del campo, las libertades y las audacias que serían insensatas o sencillamente impensables en otro estado del campo o en otro campo se convierten en normales, incluso banales. ${ }^{20}$

En este contexto, al situar estas elucubraciones en el ámbito cultural, el principal efecto del proceso de autonomización del campo sería la diferenciación cada vez más profunda de las dinámicas de producción y de recepción o consumo de la obra de arte; y en el seno de esta diferenciación, el surgimiento de un conjunto de instituciones y prácticas profesionales vinculadas entre sí en un espacio social específico, dentro del cual se lucharía por el control de la administración de la consagración artística, principal valor en juego. La gestión de la legitimidad artística no solo implicaría el control de un capital intelectual, sino el control hegemónico de unas instituciones dentro de las que se definiría desde la formación profesional del artista puro hasta la formas puras de consumo cultural; es decir, desde la escuela hasta el museo, pasando por las diferentes organizaciones e instancias de mediación del consumo artístico.

El arte puro, así, sería correlativo a la génesis de una categoría socialmente distinta de artista o de intelectual profesional, que cada vez está más inclinado a no reconocer otras reglas de acción y de interpretación de la realidad que las de la tradición conceptual que ha recibido de sus predecesores y que le proporcionan un punto de partida o de ruptura, y que, adicionalmente, le permiten las condiciones para liberar su producción de toda servidumbre extraña, ya se trate de las censuras morales o de los programas estéticos de una iglesia o de una corporación, preocupados más por el proselitismo ideológico o el control académico, o de los encargados de los poderes políticos, inclinados a ver en el arte un instrumento de propaganda. ${ }^{21}$

20. Bourdieu, Las reglas del arte..., 327.

21. Véase Pierre Bourdieu, Creencia artística y bienes simbólicos. Elementos para una sociología de la cultura (Buenos Aires: Aurelia Rivera, 2003), 85 y ss. 


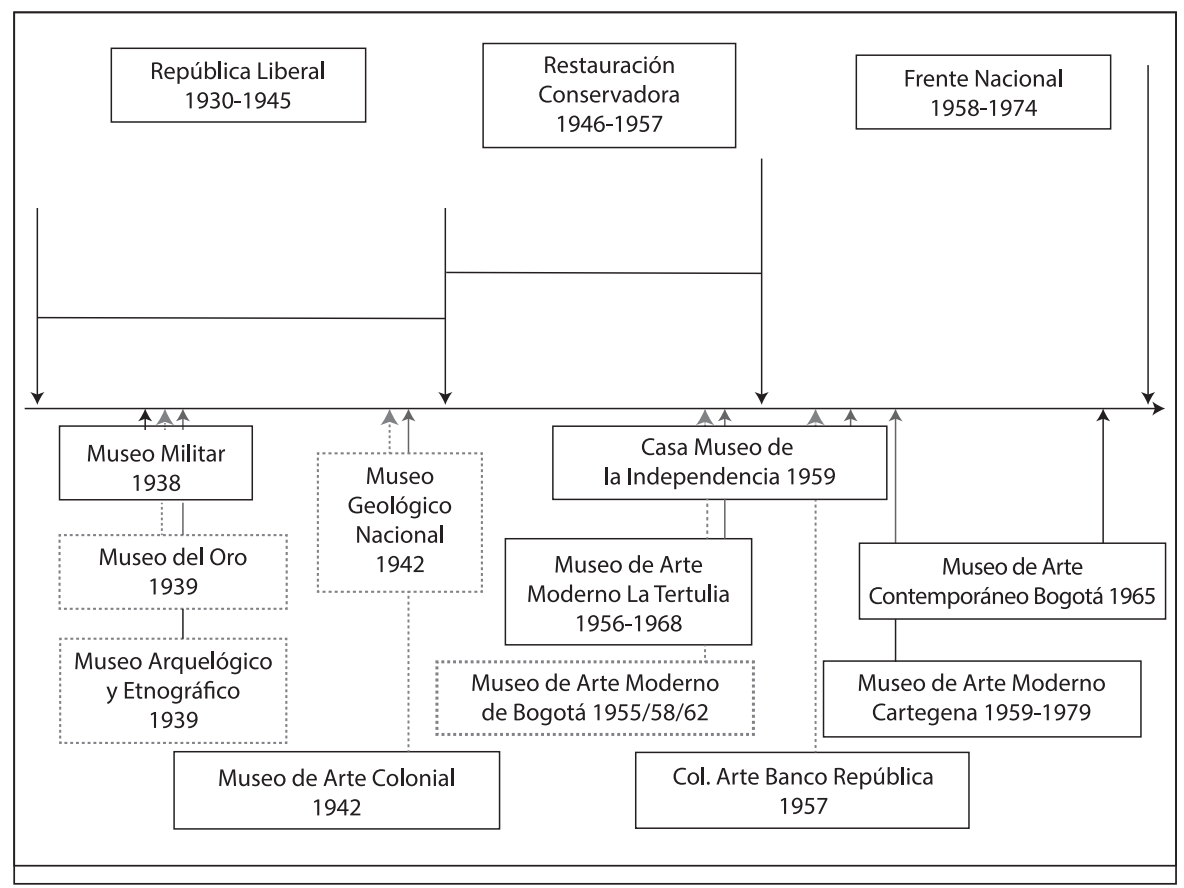

Figura 2. Línea del tiempo n. ${ }^{\circ} 1$. Fundación de algunas instituciones museológicas colombianas.

Desde esta perspectiva, si se entendiera la modernización del campo cultural de forma más o menos general como el proceso complejo y contradictorio de autonomización del campo artístico, no solo se podría desmantelar la reducción de la definición modernista de la modernidad cultural antes señalada, sino que aparecerían nuevos y complejos objetos de estudio. Entre muchos otros: la profesionalización del artista (historia de la educación artística y de las escuelas de arte), la diferenciación de las prácticas profesionales asociadas al arte (historia de la crítica de arte, del mercado del arte, del coleccionismo, la conservación y la restauración, la gestión cultural, etc.), la formación de los públicos y audiencias para el arte (historia de la educación museal), las prácticas museológicas (historia del coleccionismo, historia de la curaduría, y de los espacios museológicos), las revistas culturales (historia del consumo cultural), la apropiación del arte internacional; todo ello matizado por el análisis de las relaciones de poder nacionales e internacionales dentro y a través de las cuales se han definido las "obras de arte" en el ámbito nacional. El proceso de autonomización del campo del arte sería entendido como la instauración, constitución y desarrollo de un complejo espacio 


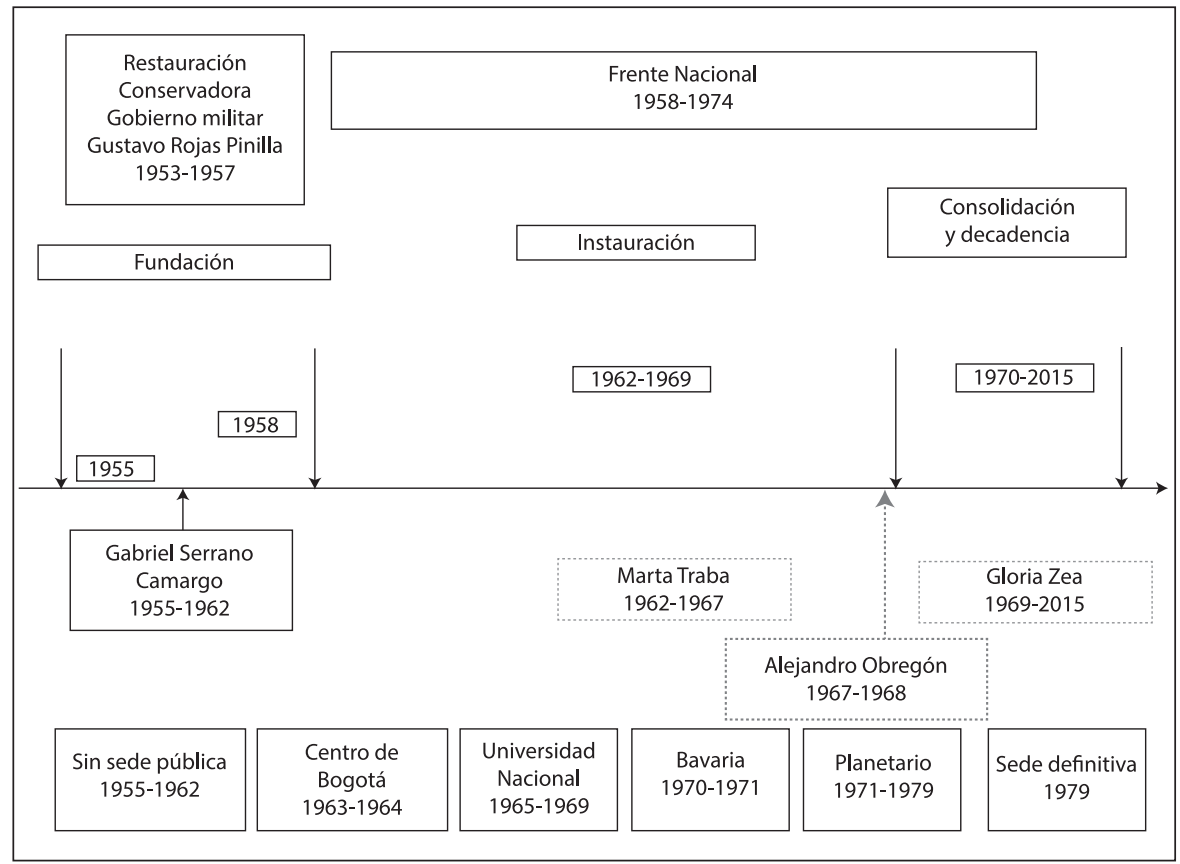

Figura 3. Línea del tiempo n. ${ }^{\circ}$ 2. Referencias temporales básicas de la trayectoria institucional del Museo de Arte Moderno de Bogotá.

social, de un contradictorio lugar de lucha por el control y monopolio de la instancias de consagración artística, articulado en una dinámica histórica de larga duración a los procesos de articulación del capitalismo en el ámbito específicamente cultural.

Del relato de una modernidad construido básicamente a partir de la crónica de las vicisitudes de la voluntad artística, se pasaría a una narración del proceso histórico en donde la modernización cultural, al menos en el caso colombiano, aparecería como el efecto social e histórico del trabajo y de las pugnas de varias generaciones de profesores, artistas, críticos, galeristas, coleccionistas, funcionarios y organizaciones culturales, en su paulatina y contradictoria adaptación a los formatos de la producción capitalista. De una modernidad fundada por el genio creador de Alejandro Obregón (1920-92), como lo quisiera, por ejemplo, Marta Traba, ${ }^{22}$ se pasaría a un proceso social cuya génesis se remontaría posiblemente a la creación de la Escuela de Be-

22. Véase Marta Traba, Historia abierta del arte colombiano (Cali: Museo de Arte Moderno La Tertulia, 1974). 
llas Artes en 1886, tal y como lo proponen autores más contemporáneos; ${ }^{23}$ es decir, al primer espacio de formación y diferenciación profesional del artista frente al artesano.

En este espacio narrativo de larga duración, la fundación de los primeros museos de arte moderno, a mediados del siglo XX, en Colombia, entonces no sería fruto de la voluntad mesiánica de ciertos sujetos privilegiados y superdotados, sino un efecto del complejo proceso de diferenciación del campo cultural; sería el resultado de las luchas protagonizadas por varios agentes dentro del campo cultural, y, en este sentido, sería consecuencia de una enmarañada y tupida trama de variables sociales y de intereses, que lentamente habría dado como resultado la relativa diferenciación del campo artístico con respecto a otros campos de poder y de producción cultural.

En este contexto historiográfico, la fundación y consolidación institucional del Museo de Arte Moderno de Bogotá se puede representar, ya no como el resultado de la adánica voluntad y pertinaz gestión de Marta Traba, sino como el efecto de las pugnas de las élites intelectuales y artísticas, en medio de las dinámicas políticas que van desde la crisis y final caída del gobierno conservador del general Gustavo Rojas Pinilla (1953-1957), hasta la instauración y consolidación del Frente Nacional (1958-1974); dentro de las cuales, claro que sí, Traba tuvo un lugar protagónico, como agente carismático dominante que era. Capitalizando las dinámicas precedentes de la autonomización del campo cultural, un grupo de intelectuales y artistas, apoyados por agentes provenientes del campo político y financiero, logró consolidar una serie de procesos culturales que se instauraron durante la República Liberal $(1930-1946),{ }^{24}$ y que determinaron, ya hacia los años sesenta, aunada a la emergencia de un pequeño pero significativo público urbano, casi todo de origen universitario, la instauración hegemónica del arte modernista y, más allá, la construcción de un discurso historiográfico de hondas consecuencias dentro de las políticas públicas de coleccionismo y del mercado del arte de las siguientes décadas.

Aunque los proyectos y procesos de modernización de la sociedad colombiana en el ámbito político, económico, cultural y social liderados por el Partido Liberal en el período que va de 1930 a 1946, con la significativa participación de intelectuales y artistas, enfrentó una gran resistencia por parte de sectores clericales y conservadores, y en todas las regiones tuvieron un grado de evolución muy diferenciado, es importante tener en cuenta que allí en donde el capitalismo industrial y financiero había logrado cotas más

23. Véase Acuña Prieto, "El papel periódico...".

24. Véase Renán Silva, República liberal, intelectuales y cultura popular (Medellín: La Carreta, 2005). 
altas de desarrollo, es decir en Bogotá y Cali, se establecieron las instituciones de arte moderno con mayor capacidad institucional del país: el Museo de Arte Moderno de Bogotá, el Museo de Arte La Tertulia, en Cali, y, también en Bogotá, lo que hacia finales del siglo XX se llamará "Museo de Arte" del Banco de la República.

El Museo de Arte Moderno de Bogotá se habría configurado dentro de la escena cultural capitalina como el efecto de la coincidencia de los intereses de un grupo de artistas, críticos e intelectuales, apoyados por un grupo de políticos y empresarios, y habría instaurado, dentro del naciente contexto del Frente Nacional, un proyecto cultural cuya principal meta habría sido la legitimación de los artistas comprometidos con el estudio y apropiación de las poéticas de las vanguardias europeas, la construcción de un proyecto poético propio fundado en la reinvención de lo real y en la constitución de un estilo personal. La materialización de una institución museológica que además de administrar un espacio de consagración autónomo, a la postre también configuraría un público, tendría como consecuencia el desarrollo de una política de largas y complejas consecuencias, dentro del desarrollo de la historia del arte colombiano.

Si en 1955, el grupo de agentes aunados alrededor de la idea de fundar un nuevo museo en Bogotá acuden a la tutela del Estado nacional para concretar su iniciativa, en una coyuntura política que parecía prestarse muy bien para perpetuar la tendencia internacional que ya había impuesto el ejemplo del Museo de Arte Moderno de Nueva York, y que, en muchos sentidos, ya había tenido impacto en São Paulo (1948) y en Río de Janeiro (1948), ${ }^{25}$ para 1962, la situación del campo cultural en Bogotá permite echar a andar la institución, ya fuera de la tutela del Estado, bajo la dirección de Marta Traba, el agente cultural con el mayor capital axiológico y, en este sentido, con la mayor legitimidad social frente a las élites políticas que habían empezado a construir y consolidar el llamado Frente Nacional.

\section{LAS NARRATIVAS SOBRE LA TRAYECTORIA del Museo de Arte Moderno de Bogotá}

Dicho todo lo anterior, una de las primeras tareas que se presentan como ineludibles al análisis es el estudio de las narrativas sobre la trayectoria del Museo de Arte Moderno de Bogotá. Esta tarea tiene como fin establecer un primer escenario de discusión sobre los procesos de legitimación y autole-

25. Véase Maria Cecília França Lourenço, Museus Acolhem o Moderno (São Paulo: Editora da Universidade de São Paulo, EDUSP, 1999). 


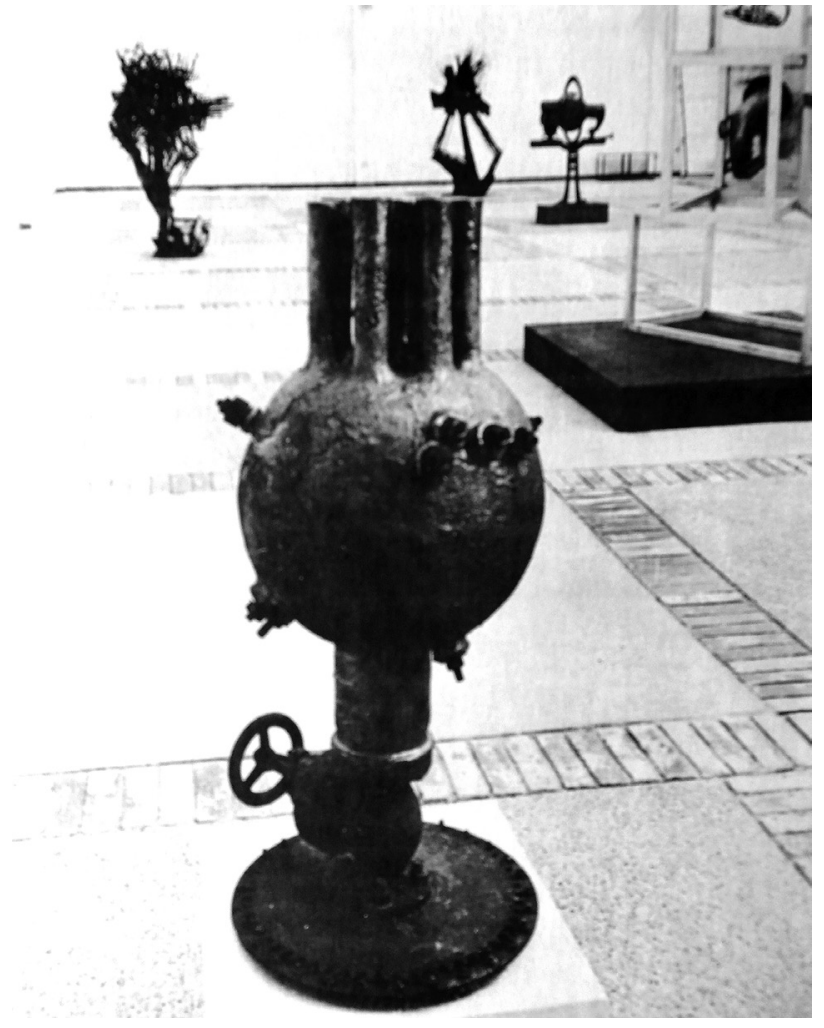

Figura 4. Vista parcial de la sala de exposiciones del segundo piso del Museo de Arte Moderno de Bogotá en el campus de la Universidad Nacional de Colombia (exposición del pintor primitivo Martínez Bravo). Foto: EGAR, tomada de Marta Traba, Museo de Arte Moderno de Bogotá (Bogotá: Universidad Nacional de Colombia, 1966).

gitimación institucional que se han configurado desde el propio Museo y desde otras instancias del campo artístico.

Acometer esta tarea dentro de esta investigación es vital para situar el derrotero histórico de construcción de los argumentos y acciones a través de los cuales se justificó la instauración y desarrollo del proyecto museológico implícito en este, dentro del vasto y complejo panorama de las luchas por el monopolio de las instancias de consagración de las obras y trayectorias profesionales de los artistas en las décadas de los cincuenta y sesenta en Colombia, que a la postre constituyeron el canon artístico y, en cierta medida, los valores hegemónicos con los que circularon las obras de arte dentro del ámbito de la producción y el consumo artísticos en la siguientes décadas, ya en la forma de historia del arte.

En términos teóricos, se trata de reseñar los argumentos a través de los cuales unos agentes muy significativos dentro del proceso de consolidación de la institución, en momentos también muy significativos, justificaron su 
acción dentro y desde del Museo de Arte Moderno de Bogotá, en el marco del proceso histórico de instauración del principio de legítima legitimación propio de las luchas de dominación en los campos de poder, ${ }^{26} \mathrm{y}$, en concomitancia, dentro del proceso de monopolización de las tareas de consagración artística. Se trata de dilucidar a través del análisis histórico-crítico la forma cómo unos agentes particulares (sujetos y organizaciones) participaron dentro de las disputas por el monopolio del privilegio de determinar qué producciones y qué artistas eran dignos de ser escenificados en la esfera pública letrada, ${ }^{27}$ lugar fundamental de constitución del valor tanto simbólico como económico de los artefactos estéticos que se presentan y representan como "obras de arte" en el espacio social directamente vinculado al campo artístico en el medio colombiano.

Como correlato de este trabajo, también se trata de determinar los mecanismos de exclusión simbólica y material que operaron con férrea eficacia para ocluir las trayectorias profesionales de los artistas que no se acomodaron a los valores impuestos por los agentes triunfantes dentro de las luchas de dominación del campo cultural. En últimas, se busca dilucidar el proceso institucional a través del cual determinados agentes monopolizaron la tarea de administrar la canonización artística y, más allá, la de instaurar una gramática narrativa hegemónica dentro de la memoria y el imaginario colectivos sobre el valor de lo que, por efecto del mismo campo, se reconoció y definió como "obra de arte" en el ámbito colombiano.

26. Véase Bourdieu, Meditaciones pascalianas.

27. En seguimiento de estas ideas, véase Ángel Rama, La ciudad letrada (Montevideo: ARCA, 1998), y en abierto contraste con la definición de la esfera pública burguesa planteada por Jürgen Habermas, Historia y crítica de la opinión pública: la transformación estructural de la vida pública (Barcelona: Gustavo Gili, 1981), la esfera pública letrada habría sido instaurada y reproducida por el "anillo protector del poder" del imperio español en América desde el período colonial. El cerrado circuito social configurado por el funcionariado y la burocracia imperial, no solo habría asegurado la administración del poder político en las colonias americanas durante la Colonia, sino que habría establecido un espacio social público fuertemente estructurado a partir del férreo control del acceso y uso público de la lectura y la escritura, y, ya en el período republicano, habría permitido la construcción de una institucionalidad pública de carácter autoritario y excluyente, dentro de la cual estaría la institucionalidad cultural, funcional al proyecto de dominación de las oligarquías decimonónicas, cuyos diversos proyectos políticos de sociedad siempre habrían estado referidos a una noción de ciudadanía limitada por el sistema de privilegios sociales que permitían su lugar dentro de la estructura social. Esta esfera pública letrada habría sobrevivido en Colombia al menos hasta la séptima u octava década del siglo XX gracias, por una parte, a la incapacidad del Estado nacional para construir un sistema de educación masivo y verdaderamente democrático, pero sobre todo al control social ejercido en torno al acceso a la educación superior, y particularmente al carácter marginal que las políticas culturales tuvieron en el marco del desarrollo de la institucionalidad pública. 
El texto de Marta Traba que se analizará aquí pertenece a una pequeña serie bibliográfica que eventualmente instauró una narrativa institucional sobre el Museo de Arte Moderno de Bogotá. Además de Museo de Arte Moderno de Bogotá (1966), en esta serie se debe incluir: El Museo de Arte Moderno de Bogotá. Recuento de un esfuerzo conjunto (1979), de Eduardo Serrano, y El Museo de Arte Moderno de Bogotá, una experiencia singular (1994), de Gloria Zea. Sin la menor duda, aunque estos textos no fueron enunciados con una intencionalidad historiográfica explícita, de todas maneras sí instauraron las primeras narraciones de carácter histórico sobre la trayectoria institucional de este museo y, más allá, configuraron las primeras periodizaciones que, en varios casos, no solo justificaron los proyectos emprendidos en un momento particular por uno $\mathrm{u}$ otro funcionario dentro del mismo Museo de Arte Moderno de Bogotá, sino que, de paso, también instalaron en el imaginario del medio artístico una versión sobre el origen, fundación, consolidación e impacto de sus emprendimientos y actividades, y, sobre todo, establecieron ciertas ideas fuerza como "sentido común" de la gestión pública, frente a la totalidad de lo que hoy se denomina "sector artístico". ${ }^{28}$ Su lugar de enunciación en la mayoría de los casos fue el MAMBo y desde allí configuraron los efectos de sentido y de poder a través de los cuales se proyectaron dentro del campo social. ${ }^{29}$

28. Véase Alberto Maldonado Copello y Yolanda López Correal, Estado del arte del área de artes plásticas en Bogotá D. C. (Bogotá: Instituto Distrital de Cultura y Turismo / Alcaldía Mayor de Bogotá, 2006) y VV. AA., Compendio de políticas culturales (Bogotá: Ministerio de Cultura, 2010).

29. Queda clara, entonces, la razón por la cual no aparecen incluidas las narrativas sobre el Museo de Arte Moderno de Bogotá enunciadas en otros lugares institucionales como la academia o, para decirlo más específicamente, el medio universitario. Ahora bien, es necesario insistir en que las tesis y eventualmente los artículos publicados particularmente sobre el Museo de Arte Moderno infortunadamente replican de forma más o menos mecánicas los contenidos de lo que aquí se está definiendo como "narrativa institucional". Por ejemplo, un texto como el de Suescún Pozas, "Los museos de arte moderno..." no solo tiene un lugar de enunciación radical a los textos de Traba, Serrano y Zea, pero infortunadamente hace eco de la cadena textual que legitima la acción del Museo de Arte Moderno de Bogotá dentro del corpus ideológico construido por Marta Traba en su momento. Si bien es cierto, como los primeros, también participa en las luchas propias del campo artístico, los intereses que persigue, en general, no están relacionados con las disputas por la configuración directa del valor de la obra de arte o de la trayectoria de un determinado artista; está buscando, en cambio, situarse en el debate sobre la constitución epistemológica de los marcos teórico-narrativos generales, que bien podrían llamarse historiográficos, y que pugnan por instaurar el sentido y el lugar de la serie artística dentro de la cultura como globalidad, constituyendo, de paso, un macro-relato de los supuestos discursivos, pero también de la sintaxis y contenidos de las narraciones histórico-artísticas hegemónicas, en el marco general de profundización de la diferenciación del trabajo en el campo cultural, es decir, de la emergencia del trabajo del historiador del arte como profesión 


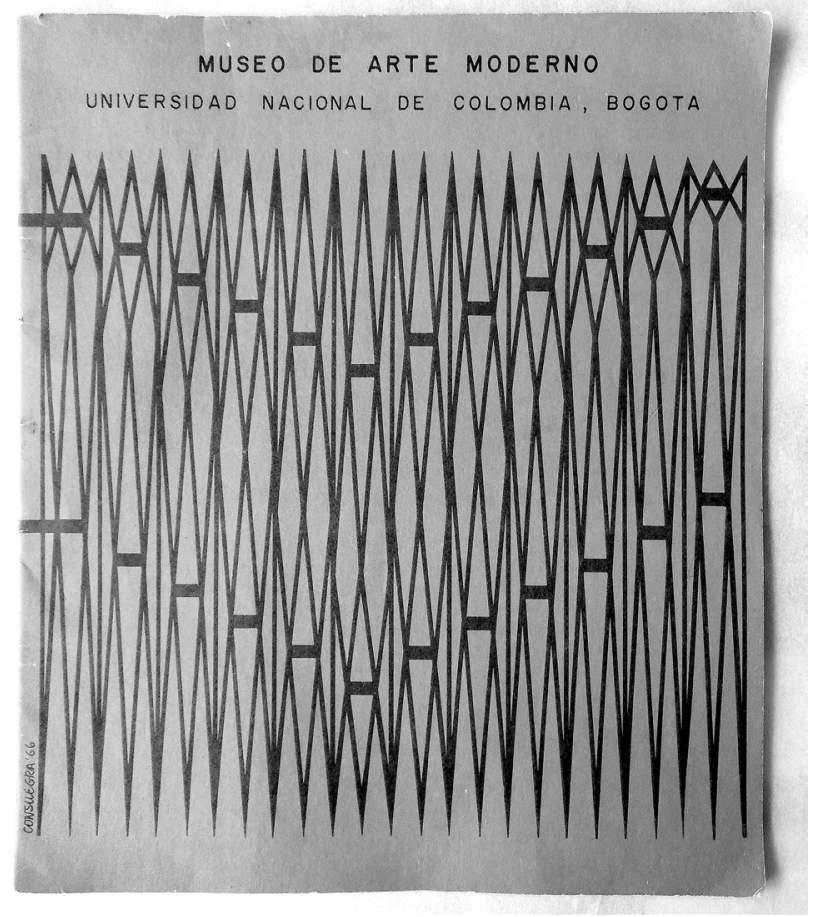

Figura 5. Carátula del informe de gestión del Museo de Arte Moderno de Bogotá editado en 1966, cuando este residía en el campus de la Universidad Nacional de Colombia. Con fotografías de EGAR, el diseño fue realizado por David Consuegra, e impreso por el Programa de Extensión Cultural y Relaciones Públicas de la Secretaría General de la Universidad, que estaba a cargo de Marta Traba y Emma Araújo, durante las rectorías de José Félix Patiño (1964-1966) y Jorge Méndez Munevar (1967-1970).

Aunque dentro de la bibliografía general sobre arte en Colombia se pueden encontrar otros textos que tocan directa o tangencialmente la trayectoria institucional de otros museos de arte o la configuración de sus colecciones, ${ }^{30}$ el análisis se ha reducido al mencionado, no solo por la relación directa que

caracterizada específicamente, a lo largo de las últimas décadas. Habría que agregar, por último, que al ser enunciado fuera del museo se trata de un texto enunciado cuya intencionalidad crítica corresponde más al ámbito propiamente profesional de las ciencias sociales que al propiamente museológico o histórico-artístico. Se trata, como ya se señaló, de un texto escrito dentro del proceso general de consolidación de la Historia del Arte como disciplina y profesión en el ámbito universitario, producido en el medio académico nacional e internacional.

30. Véase notas 3,4 y 5. 
tienen con el momento fundacional, sino con la trayectoria inicial del Museo de Arte Moderno de Bogotá en razón del origen mismo de su propia institucionalidad, y de la tipología museal que esta institución instauró en el medio nacional. Como es bien sabido en el contexto de las teorías museológicas y de las artes contemporáneas, el "museo de arte moderno" constituye un tipo de museo en sí mismo, que no solo figura toda una ideología museal dentro de sus espacios expositivos, ${ }^{31}$ sino que articula un proyecto cultural global de indudables connotaciones políticas en América Latina, particularmente a partir de la llamada Guerra Fría, período en que los Estados Unidos consolidaron su posición hegemónica en el plano internacional. ${ }^{32}$

\section{6: Marta Traba y la FUndación DE UNA NARRATIVA INSTITUCIONAL}

Desde los primeros días de su gestión como directora del Museo de Arte Moderno de Bogotá, es decir, desde octubre de 1962, Marta Traba (1923-1983) se encargó de establecer un relato retrospectivo que, pese a la cortedad de la trayectoria de la institución para esa fecha, no solo fue acotando el ámbito de su acción museológica dentro del panorama artístico nacional, sino que fue prefigurando el significado y, por tanto, los argumentos de la autolegitimación institucional de su derrotero como organización cultural frente a la totalidad de los agentes del campo artístico. Esta doble tarea aparece articulada en el discurso de Traba a partir de la instauración de una gramática temporal que tácitamente divide esa trayectoria institucional en dos momentos: desde

31. Véase, por ejemplo, Brian O'Doherty, Inside the White Cube. The Ideology of the Gallery Space (Santa Mónica: The Lapis Press, 1986); John Elderfield et al., Imagining the Future of the Museum of Modern Art (Nueva York: Museum of Modern Art of New York, 1998); Allan Wallach, Exhibiting Contradiction. Essays on the Art Museum in the United States (Boston: The University of Massachusetts Press, 1998); Sybil Gordon Kantor, Alfred H. Barr Jr. and the Intellectual Origins of the Museum of Modern Art (Boston: MIT, 2002); Duncan, Rituales de civilización.

32. Véase Max Kozloff, "American Painting During the Cold War", Artforum, n. 9 (mayo 1973): 43-54; Eva Cockcroft, "Abstract Expressionism, Weapon of the Cold War", Artforum, n. 10 (junio 1974): 39-41; Lourenço, Museus Acolhem...; Andrea Giunta, Vanguardia, internacionalismo y política. Arte argentino en los años sesenta (Buenos Aires: Paidós, 2001); Arte de posguerra. Jorge Romero Brest y la revista Ver y Estimar, comp. por Andrea Giunta y Laura Malosetti Costa (Buenos Aries: Paidós, 2005); Ana Rosas Mantecón y Graciela Schmilchuk, "Del mito de las raíces a la ilusión de la modernidad internacional". En El museo en escena. Política y cultura en América Latina, comp. por Américo Castilla (Buenos Aries: Paidós / Fundación TyPA, 2010), 145-165; y, Renata Motta, “Museos de arte en Brasil: entre lo moderno y lo contemporáneo". En ibíd., 185-215. 
1955 hasta 1962, y desde 1962 en adelante; es decir, desde el año de la primera fundación del museo, en 1955, hasta su reactivación, o tercera fundación, en 1962, y desde esta última fecha en adelante. ${ }^{33}$

El análisis de esta periodización es clave no solo porque permite determinar el momento en que efectivamente arrancan las actividades públicas del museo, sino porque también permite ubicar el período en que la posición de Marta Traba se consolidó definitivamente dentro del campo artístico nacional a través de la institucionalización de su pensamiento; ${ }^{34}$ procesos inextricablemente unidos por el carácter particular de la concreción organizacional del

33. Aunque el proceso de creación y consolidación organizacional del Museo de Arte Moderno de Bogotá es complejo, baste señalar por el momento que su primera fundación se realizó mediante el Decreto n. 2057 del 28 de julio de 1955 de la Presidencia de la República, bajo el gobierno del general Gustavo Rojas Pinilla (junio de 1953-mayo de 1957). Este acto fue derogado mediante el Decreto . $^{\circ}$ 150, en mayo de 1958, ya bajo el gobierno de la Junta Militar que reemplazó en la jefatura del Estado a Rojas Pinilla. El museo fue vuelto a crear como una institución privada ante el Ministerio de Justicia, según la resolución n. ${ }^{\circ}$ 0478 de 1958 de esta entidad. Unos años más tarde, en 1962, el museo volvió a fundarse, y desde esa fecha en adelante su actividad nunca se ha visto interrumpida, a pesar de su periplo por las consecutivas sedes que ocupó, primero, en el centro de la ciudad (1963-65), luego en el campus de la Universidad Nacional de Colombia (1965-70), más tarde en el Edificio Bavaria (1970-71), y en el Planetario Distrital (1971-79), hasta arribar a su sede definitiva sobre la Avenida 26. Véase Eduardo Serrano, El Museo de Arte Moderno de Bogotá. Recuento de un esfuerzo conjunto (Bogotá: Museo de Arte Moderno de Bogotá, 1979).

34. El concepto de institucionalización, dentro del corpus teórico de Bourdieu, está directamente relacionado con el proceso de diferenciación de los campos; es decir de la autonomización del espacio social en donde se ejerce y administra un tipo específico de saber. La configuración de organizaciones en las que no solo median los intereses de los agentes particulares dentro de un campo sino que hacen posible la administración de un conocimiento o saber particular, a través de un código de comportamiento, un sistema escolar o académico, o una red de organizaciones, y, con ello, la gestión de los procedimientos que determinan socialmente la construcción de los habitus de los dominantes, pero también la gestión de la consagración, está en directa relación con la naturalización de tipos de violencia simbólica aceptadas normalmente, es decir, incorporada por la mayoría de los agentes dentro de un campo particular. En este sentido, la institucionalización está en directa relación con las dinámicas de legitimación del ejercicio del poder y de la administración del monopolio de las posiciones dominantes, disimulando el carácter arbitrario de las relaciones de fuerza; es decir, su historicidad. Así, la imposición de una posición particular o de un conjunto de posiciones concomitantes supone su asunción como teoría, escuela, misión o visión organizacional, o como norma propia del campo, y más allá, como organización, en la forma de institutos, universidades, museos, asociaciones, agremiaciones, corporaciones, sindicatos, laboratorios, etc. La institucionalización supone, entonces, la concentración de capital simbólico y, en consecuencia, su administración a través de la despersonalización, burocratización, ritualización y, sobre todo, anonimato y universalización; dinámicas que, según Bourdieu, también están en la base de la emergencia y consolidación del Estado. Véase Pierre Bourdieu, Razones prácticas. Sobre la teoría de la acción (Barcelona: Anagrama, 1997). 
Museo de Arte Moderno de Bogotá, pero también por la incorporación en esta de la ideología modernista defendida por Traba; es decir, por la particular interpretación que Traba daba al modernismo artístico en ese momento.

A través de la ideación, concreción y administración del Museo de Arte Moderno de Bogotá, pero sobre todo de su programa educativo, Traba logró institucionalizar su posición, perpetuándola en la forma de un discurso ritualizado burocráticamente, pero también universalizado en la forma de un proyecto museológico que despersonalizó sus intereses, otorgándoles el embalaje de una misión y visión organizacionales, que prefiguraron, materializaron y potenciaron las principales ideas-fuerza que ella había articulado a lo largo de su trayectoria profesional.

Los argumentos a partir de los cuales se justificó la administración de la acción de este museo, en este sentido, fueron planteados y ampliados en forma de discurso misional, desde el corpus intelectual construido por Traba a lo largo de la década anterior, pero sin su adscripción autoral explícita; es decir, a través de la disolución de su adscripción autoral en la del museo. Al despersonalizar su posición y situar sus propios intereses dentro de un discurso que aparentemente obedece a la lógica universal y, por tanto, legítima, de la educación artística de los públicos museales, Traba logró soslayar las fuertes resistencias que hasta ese momento habían tenido sus planteamientos dentro del medio artístico nacional, ${ }^{35}$ configurando, de paso, una nueva posición institucional que se acomodaba perfectamente a su trayectoria, pero sobre todo a sus intereses.

Por otra parte, al conquistar esta nueva posición institucional dentro del campo artístico, ella también logró situar en un plano organizacional no solo su valoración de la obra de arte y de la trayectoria de los artistas colombianos, sino que empezó a establecer un canon artístico decididamente modernista y un proyecto de proselitismo pedagógico que perpetuaba el trabajo "educativo" que ella venía realizando como profesora de historia del arte en la Universidad América, la Universidad de los Andes y en la misma Universidad Nacional de Colombia, y que desde 1954, cuando ella empezó a situarse dentro del campo artístico colombiano, ya apuntaba a la configuración del gusto en clave modernista de la fracción dominante de las élites sociales y de un fragmento muy significativo de las clases medias que en aquella época accedieron al sistema universitario público y privado.

Así, la asunción de la posición de Marta Traba a discurso institucional, como fundamento y fin de un proyecto museológico inédito en el campo

35. Véase Christian Padilla Peñuela, La llamada de la tierra. El nacionalismo en la escultura colombiana (Bogotá: Fundación Gilberto Alzate Avendaño / Alcaldía Mayor de Bogotá, 2008). 
cultural, supuso, a lo largo de la siguiente década, la reestructuración de la administración de las instancias de legitimación artística que hasta ese momento detentaban la dirección de la Escuela de Bellas Artes de la Universidad Nacional de Colombia, la dirección del Museo Nacional de Colombia y la Dirección de Extensión Cultural y de Museos del Ministerio de Educación.

Aunque las galerías de arte, ${ }^{36}$ los proyectos expositivos independientes organizados por los propios artistas y, sobre todo, el trabajo realizado a lo largo de las anteriores décadas por el grupo de críticos modernistas que antecedieron a Marta Traba ya habían empezado a gestar un cuestionamiento y deslegitimación correlativos, ${ }^{37}$ es la consolidación del Museo de Arte Moder-

36. Aunque las investigaciones sobre el mercado del arte en Colombia son muy incipientes, los trabajos de Guillermo Vargas Quisoboni (2002), Santiago Rueda Fajardo (2009) y Julián Camilo Serna Lancheros (2011) permiten establecer un panorama inicial sobre el papel que han desempeñado las galerías de arte en nuestro medio. Para el contexto objeto de esta investigación véase Julián Camilo Serna Lancheros, El valor del arte: una historia de las primeras galerías de arte en Colombia (1948-1957) (Bogotá: Universidad EAN, 2011) que, sin la menor duda, es el más pertinente. Precisamente, a propósito de la situación del mercado del arte al finalizar la década de los años cuarenta en Bogotá, Serna Lancheros afirma: "como alternativa al salón oficial, existían pequeñas salas de exhibición, propiedad de sociedades profesionales como la Sociedad de Ingenieros y la Sociedad Colombiana de Arquitectos que eran prestadas para que los artistas organizaran muestras de su propia obra, y espacios que eran propiedad del gobierno como la Biblioteca Nacional, los pasillos del Teatro Colón, y la recién inaugurada sede del Museo Nacional de Colombia". Ibíd., 4. El polaco Casimiro Eiger (1909-87), uno de los críticos de arte más connotados de la época en el país, decía a propósito de las salas de exhibición que existían en Bogotá en 1960, además de las administradas por las galerías El Callejón, de su propiedad, y la Galería Buchholz: "Existen actualmente y funcionan en la capital las siguientes galerías o salas de exhibición: Museo Nacional (cuatro salones y dos galerías abiertas), Biblioteca Nacional (dos salones), Biblioteca Luis Ángel Arango (dos salones), Sociedad Económica de Amigos del País y Universidad de América, todas ellas de índole oficial o pertenecientes a entidades públicas (y, por consiguiente, gratuitas), así como algunas salas ocasionales (pero también gratuitas): la del Instituto de Cultura Hispánica, la de la Sociedad de Arquitectos y algunas otras". Véase Casimiro Eiger, Crónicas de arte colombiano 1946/1963 (Bogotá: Banco de la República, 1995), 689 y 690.

37. La defensa del modernismo en la plástica colombiana podría remontarse a la primera mitad del siglo XX con la obra de Baldomero Sanín Cano (1861-1957), Luis Vidales (1900-90), Gustavo Santos (1892-1967), Jorge Zalamea (1905-69) y Gabriel Giraldo Jaramillo (1910-78). Un segundo grupo de letrados modernistas estaría conformado por los críticos que comenzaron a publicar sus comentarios hacia mediados de los años cuarenta y principios de los años cincuenta; es decir, entre otros, Walter Engel (1908- ), el ya citado Casimiro Eiger, Eugenio Barney-Cabrera (1917-80), Clemente Airó (1918-75), Jorge Gaitán Durán (1924-62), y la propia Marta Traba. La última oleada de críticos modernistas estaría conformada por nombres como el de Germán Rubiano Caballero (1938- ), Galaor Carbonell (1938-96), Luis Fernando Valencia (¿?), Darío Ruiz Gómez (1936- ), Álvaro Medina (1941- ), y Ana María Escallón (1954- ). Véase Jaramillo Jiménez, “Una mirada a los orígenes...", 3-38; López Rosas, Miguel Díaz Vargas... 
no de Bogotá la que va a determinar la reestructuración total del campo artístico a lo largo de los años sesenta y setenta, al lado, claro está, del surgimiento y consolidación de otras instituciones análogas, como la Biblioteca Luis Ángel Arango, ${ }^{38}$ también en Bogotá; el Museo de Arte Moderno La Tertulia, sobre todo a través de la organización y realización de los Festivales de Arte en Cali a lo largo de los años sesenta; ${ }^{39}$ y la realización de eventos artísticos como los Salones Interamericanos de Pintura, organizados por el grupo de letrados y artistas aunados alrededor del Centro Artístico de Barranquilla. ${ }^{40}$

38. La actividad cultural del Banco de la República se remonta hasta mediados de los años treinta, cuando esta institución financiera abre al acceso del público la biblioteca sobre asuntos relacionados con la economía y la hacienda pública que venía funcionando para uso exclusivo de sus empleados, desde su fundación, en 1923. Véase Luis Fernando Molina Londoño, Historia de una empresa cultural. Biblioteca Luis Ángel Arango (1957-2007) (Bogotá: Banco de la República, 2013). Pero es con la realización del Salón de Arte Moderno, en 1957, organizado con ocasión de la celebración de la 5. ․ Reunión de los Bancos Centrales del Continente Americano, durante la cual se había previsto la inauguración de la sede de la Biblioteca Luis Ángel Arango en el Barrio La Candelaria, cuando se abrieron las puertas de la sala de exposiciones de esta institución y se inició la construcción de su colección de arte. Véanse Sylvia Juliana Suárez Segura, Salón de arte moderno 1957: 50 años de arte en la Biblioteca Luis Ángel Arango (Bogotá: Banco de la República, 2007), 8; y Ramírez Botero, El arte en Cartagena..., 16.

39. El origen del Museo de Arte Moderno La Tertulia es la Corporación La Tertulia para la Enseñanza Popular, Museos y Extensión Cultural, fundada en Cali en marzo de 1956. Véase Maritza de Urdinola y Miguel González. Museo de Arte Moderno... Desde esa fecha, esta institución desarrolló actividades culturales de diversa naturaleza, dentro de las que se contaban además de conferencias de toda índole, proyecciones de cine y exposiciones de artes plásticas. Estas actividades culturales derivaron, a lo largo de la década de los sesenta, hacia la organización del Festival de Arte de Cali, y finalmente se concretarían, en 1968, en la construcción de la sede definitiva del Museo, en 1968. Véase González Gallego, "El Museo La Tertulia...".

40. Las recientes investigaciones adelantadas por Isabel Cristina Ramírez Botero han permitido abrir todo un campo de indagación histórico-artística sobre la institucionalidad asociada al arte modernista en Barranquilla y Cartagena. En uno de sus más recientes trabajos, la investigadora señala: "Si hacemos una revisión muy general de las fechas en las que fueron surgiendo las primeras instituciones modernas del arte en ambas ciudades, encontramos una importante concentración de eventos inaugurales entre 1940 y 1962. A muy grandes rasgos podemos mencionar el nacimiento de las escuelas de bellas artes de Barranquilla (1941) y de Cartagena (1957), la Primera Feria de Arte de Cartagena (1940), y el Salón de Artistas Costeños en 1945, con periodicidad anual hasta 1953, las galerías de arte moderno de Cartagena (1955) y de Barranquilla (1959), el Salón Interamericano de Arte Moderno en Cartagena (1959), los Anuales de Pintura de Barranquilla con una versión nacional (1959), y dos interamericanas (1960 y 1963), y, finalmente, los Museos de Arte Moderno de Cartagena (1959) y de Barranquilla (1960)". Isabel Cristina Ramírez Botero, Ampliando del mapa. Nuevas aproximaciones a los procesos locales y regionales en la historia del arte moderno en Colombia. El caso de Barranquilla y Cartagena (Bogotá: Instituto Distrital de las Artes de Bogotá / Universidad Jorge Tadeo Lozano, 2011), 18. 
Al instaurar un principio de monopolización de las instancias de legitimación artística a través de la mediación de la construcción de un público de gusto modernista, la constitución de un canon también modernista y, por último, la administración de las posibilidades de consagración internacional de los artistas colombianos, la labor de Marta Traba quedó completamente blindada como un trabajo de carácter fundacional, revestido, al mismo tiempo, por una ideología carismática y mesiánica que todavía hoy no deja de reproducirse, incluso en los estudios académicos supuestamente más críticos y documentados, y dentro del imaginario de la crítica y del público letrado de aquel momento y, eventualmente, del público de las décadas posteriores. ${ }^{41}$

Es preciso adelantar algunos datos significativos para interpretar la posición de Traba a principios de los años sesenta, para matizar su posición: desde su llegada al país, en 1954, ella desarrolló una actividad crítica y pedagógica que le permitió construir un capital cultural y social de importancia significativa para lograr establecer, una década después, una posición dominante en el campo artístico nacional. A su intensa actividad como curadora, gestora cultural, manager, presentadora de televisión, galerista y crítica de arte, roles profesionales muy poco diferenciados en la época, ella sumó una profusa actividad social no solo dentro de los círculos intelectuales en los cuales se movía su compañero sentimental en esa época, el escritor y periodista Alberto Zalamea Costa (1929-2011), sino dentro de la fracción de las élites bogotanas ideológicamente más sensibles a las propuestas del modernismo plástico. ${ }^{42}$ Aunque su presencia en el medio colombiano solo se reduce a quince años, entre 1954 y 1969, esta fue suficiente no solo para establecer un parte aguas dentro del imaginario histórico del arte nacional sino para configurar un legado institucional que, en las décadas posteriores, permitió

41. Tal vez el autor más notoriamente comprometido con la reproducción de la ideología carismática asociada a la obra de Marta Traba es Efrén Giraldo. En los estudios que ha dedicado a la obra de Traba recae una y otra vez de forma acrítica en la repetición de todos los lugares comunes de la valoración que se le ha otorgado a la presencia y acción de esta en el medio colombiano, sobre todo por la perspectiva inmanentista que él pone en funcionamiento a la hora de desarrollar sus estudios. Sus conclusiones carecen de una teoría del autor que permita trascender en su análisis no solo el carácter absoluto con el que asume la totalidad de la obra de Traba sino el anacronismo con el que interpreta los textos particulares a partir de los cuales construye su interpretación. Particularmente en el libro Efrén Giraldo, Marta Traba: crítica del arte latinoamericano (Medellín: La Carreta / Universidad de Antioquia, 2007), evidencia su apego absoluto a la interpretación mesiánica que la institucionalidad cultural oficial colombiana ha dado al lugar de Traba dentro de la emergencia y consolidación de la modernidad plástica en el país, pero sobre todo a su función como pivote ideológico de la construcción del canon modernista en Colombia.

42. Véase Victoria Verlichak, Marta Traba. Una terquedad furibunda (Buenos Aires: Universidad Nacional de Tres de Febrero / Fundación PROA, 2001); y, López Rosas, Emma Araújo de Vallejo... 
la naturalización pero también el achatamiento de su posición como piso conceptual de las dinámicas de interpretación histórica y de valoración crítica del arte colombiano, particularmente en relación con los procesos de construcción de las colecciones públicas de arte, en donde sus alumnas y amigas tuvieron una altísima injerencia, a lo largo de las décadas de los setenta, ochenta y noventa. Así, sus ideas, tamizadas por el control ideológico a que fueron sometidas en el proceso de consagración de su figura, van a tener un impacto sustancial en el proceso de canonización de los artistas modernistas por más de tres décadas y van a determinar, en parte, la sintaxis básica a través de la cual se estructuró la narración histórico-artística de las historias modernistas del arte en el país.

Para 1964, Traba ya era denominada como la "papisa del arte colombiano" y, sin duda, era una crítica de arte consagrada, "temida y apasionadamente respetada". ${ }^{43}$ Después de una intensa y agitada trayectoria profesional que la llevó a enfrentarse en crudas polémicas con artistas y agentes claves del campo artístico colombiano a lo largo de la década anterior, ${ }^{44}$ ella, además de dirigir el Museo de Arte Moderno de Bogotá y fungir como su única curadora, se desempeñaba como cabeza del Programa de Extensión Cultural y Relaciones Públicas de la Secretaría General de la Universidad Nacional de Colombia, cargo al había sido llamada por el rector de ese momento, el médico José Félix Patiño Restrepo (1927). Esta instancia, administrada al lado de su alumna y amiga Emma Araújo de Vallejo (1930), le permitió un margen de gestión institucional nunca antes monopolizado por agente alguno dentro del campo artístico nacional, movilizando a su favor y del Museo de Arte Moderno de Bogotá, el capital cultural de una de las instituciones educativas más significativas de la época. Así, al concentrar bajo su dominio el proceso de configuración y consolidación del proyecto museológico del "joven" Museo de Arte Moderno de Bogotá y la programación y realización de la actividad cultural de la Universidad Nacional de Colombia, en un momento particularmente significativo de los procesos de modernización de la administración universitaria, la reforma académico-administrativa liderada por Patiño Restrepo durante su paso por la rectoría de la institución (19641966), Marta Traba logró articular una sinergia institucional de hondo calado dentro de la vida cultura de la ciudad y el país.

Es imposible, por otra parte, no mencionar, así sea de forma sintética, la distancia que Traba empezaba a construir con respecto al tipo de modernismo que había defendido de forma radical desde su llegada a Colombia, precisamente hasta el momento en que ella entró en contacto diario con el

43. Verlichak, Marta Traba. Una terquedad..., 141.

44. Véase Padilla Peñuela, La llamada de la tierra..., 199 y ss. 
ambiente universitario, pero también con las políticas culturales de la Revolución cubana, y particularmente con el pensamiento latinoamericanista de autores como Ángel Rama (1926-1983). Según Florencia Bazzano-Nelson, a mediados de los años sesenta, Traba inició un proceso de evaluación de sus ideales estéticos, que se iniciaría con los viajes que realizó en 1963 y 1964 como jurado, conferencista u observadora de varios certámenes artísticos realizados en ciudades como Buenos Aires, Caracas, Córdoba, México D.F., Lima y Santiago de Chile, y culminaría con la publicación del texto titulado Arte latinoamericano actual (1972), más conocido por la versión que se publicó en México un año después como Dos décadas vulnerables en las artes plásticas latinoamericanas 1950-1970 (1973), y que escribió entre 1968 y 1969, mientras se movía entre Bogotá y Montevideo, preparando el desplazamiento de su residencia fuera de Colombia. ${ }^{45}$

Desde esta compleja posición, Traba configuró la misión de la nueva institución cultural alrededor de la "tarea de acercamiento del público del Museo a la producción moderna más contemporánea". ${ }^{46}$ Desde su perspectiva, el público universitario y profesionista del museo habría entrado en contacto con las obras modernas en todas las áreas y disciplinas de la creatividad artística, a través de la construcción de un panorama de la cultura contemporánea, comprendiendo, de paso, la "unidad" del contexto histórico en que estas aparecieron.

Precisamente, en uno de los primeros catálogos elaborado por el Museo a modo de informe de gestión, publicado cuando este ya había sido trasladado de su primera sede, ubicada en el centro de la ciudad, al campus de la Universidad Nacional de Colombia, Traba afirma:

El Museo de Arte Moderno de Bogotá está abierto al público desde noviembre de 1963. Desde entonces ha realizado tres ciclos de educación audiovisual, de cuatro meses de duración cada uno, en los cuales intervinieron las figuras más importantes de la cultura contemporánea colombiana. La finalidad de dichos ciclos fue acercar el público a las distintas expresiones de la creación moderna, en el campo de las artes plásticas, la música, el cine de arte, el teatro, la literatura y la música, para que confrontaran las coincidencias entre unas y otras formas del pensamiento creador y entendieran el siglo XX como una cultura unitaria y peculiar. La asistencia promedio a estas sesiones fue de doscientas personas por reunión, la mayoría de los cuales entre estudiantes y profesionales [sic]. Al mismo tiempo que los ciclos audiovisuales intentaban esclarecer este panorama general, en la sede del

45. Véase Florencia Bazzano-Nelson, "Cambios de margen: las teorías estéticas de Marta Traba". En Marta Traba, Dos décadas vulnerables en las artes plásticas latinoamericanas 1950-1970 (Buenos Aires: Siglo XXI Editores, 2005 ), 9 y ss.

46. Véase Marta Traba, Museo de Arte Moderno y la Universidad Nacional (Bogotá: Museo de Arte Moderno / Universidad Nacional de Colombia, 1966), 4. 
Museo facilitada por Intercol, se llevaba a cabo un programa ambicioso de exposiciones nacionales y extranjeras, escogidas de acuerdo con un criterio y orientación claramente definido. En lo nacional, el criterio fue presentar la mayor cantidad posible de artistas jóvenes cuyas obras significaran nuevas posiciones dentro del arte colombiano, y realizar una exposición retrospectiva durante cada semestre. ${ }^{47}$

Según el texto citado, adicionalmente a estas labores, el museo habría asumido la tarea de construir un panorama continental de la producción artística a través de dos estrategias: a) la presentación de "las primeras figuras de los distintos países latinoamericanos con el propósito de dar al público la dimensión más lógica, que es la continental"; y b) la mediación de la carrera de los artistas colombianos en el exterior. A propósito de esta segunda meta, en el mencionado catálogo se decía: “Es intención del Museo convertirse cada vez más en el organismo intermediario entre los artistas nacionales y las bienales que se realizan en el extranjero, para que Colombia siempre esté representada de la mejor manera posible y no se pierdan, como ocurre en la actualidad, interesantes oportunidades de participación". ${ }^{48}$

A este conjunto de tareas, que asumieron la forma de objetivos misionales, se debe agregar la configuración de una colección que para 1966, según el mismo documento, alcanzaba las sesenta y tres obras:

Mediante la exposición regular de la colección permanente, el Museo pretende ubicar al público en la órbita que le es inmediata, la de su propio país, y en la que es mediata, la de su continente, en la convicción de que sólo alcanzando una conciencia nacional y continental se logrará formular una cultura de importancia. Llevando a término todas estas actividades, el Museo cree cumplir el cometido propuesto; educar estéticamente, en los valores de la cultura contemporánea, a los más aptos y mayores sectores de público. Desea convertirse, paulatinamente, en el centro cultural más importante de la ciudad, del cual emane una orientación justa que vaya enseñando los valores verdaderos y adoctrinando acerca de las expresiones nacionales. ${ }^{49}$

47. Intercol es el nombre que asumió, en Colombia, la International Petroleum Co., subsidiara de la empresa estadounidense Standard Petroleum Company. Esta empresa multinacional financió durante un año el alquiler de la primera sede del Museo de Arte Moderno de Bogotá en el centro de la ciudad. En un capítulo posterior se analizarán las dinámicas de mecenazgo y patrocinio que implementaron las directivas del Museo y su relación con su proyección internacional, en el marco de la organización y realización del Salón ESSO de Artistas Jóvenes, celebrado en 1964, con la coordinación del curador y crítico de arte de origen cubano José Gómez Sicre (1916-1991), a la sazón director de la Sección de Artes Visuales de la Organización de Estados Americanos (OEA). Véase Nadia Moreno Moya, Arte y juventud. El Salón ESSO de artistas jóvenes en Colombia (Bogotá: IDARTES, 2013). Traba, El Museo de Arte Moderno..., 4.

48. Ibíd., 10.

49. Ibíd., 11. 
Cuadro 1. Exposiciones programadas por el Museo de Arte Moderno (1963-65)

\begin{tabular}{|c|c|}
\hline Año & Nombre de la exposición \\
\hline 1963 & $\begin{array}{l}\text { Antonio Roda } \\
\text { Arte venezolano contemporáneo } \\
\text { Tres argentinos: Antonio Berni, Carlos Uría y Carlos Alonso }\end{array}$ \\
\hline 1964 & $\begin{array}{l}\text { Colección Lemaitre } \\
\text { Fernando Botero } \\
\text { Guillermo Wiedemann } \\
\text { Beatriz González } \\
\text { Alberto Gutiérrez } \\
\text { Leonel Góngora } \\
\text { Primer Salón Intercol de Artistas Jóvenes } \\
\text { Eduardo Ramírez Villamizar } \\
\text { Feliza Bursztyn } \\
\text { Nereo } \\
\text { Fernando de Szyszlo } \\
\text { Oscar Pantoja } \\
\text { Homenaje a Miguel Ángel }\end{array}$ \\
\hline 1965 & $\begin{array}{l}\text { Nuevas posiciones del arte actual en Colombia } \\
\text { Luciano Jaramillo (pintura) } \\
\text { Norman Mejía (pintura) } \\
\text { Pablo Solano (pintura) } \\
\text { Fanny Sanín (pintura) } \\
\text { Pedro Alcántara Herrán (dibujos) } \\
\text { Hernando Tejada (escultura en madera) } \\
\text { Bernardo Salcedo } \\
\text { Carlos Rojas } \\
\text { Graciela Samper de Bermúdez } \\
\text { Primer Salón Universitario } \\
\text { Primera exhibición de escultura al aire libre } \\
\text { Premios y rechazados del XVII Salón Nacional } \\
\text { Retrospectiva de Edgar Negret } \\
\text { Antonio Roda } \\
\text { Sofía Urrutia } \\
\text { Enrique Tábara } \\
\text { Arte ecuatoriano contemporáneo }\end{array}$ \\
\hline
\end{tabular}

Cuadro elaborado a partir de Marta Traba, Museo de Arte Moderno (Bogotá: Universidad Nacional, 1966). Según este catálogo, para 1966, estaban programadas las siguientes exposiciones: Mateo Manaure, Jacobo Borges, María Luisa Pacheco, Lola Fernández, pintores nipobrasileros y pintura actual chilena. 
El programa académico del museo, su agenda expositiva, que para 1965 ya había realizado 33 muestras (cuadro 1), así como la configuración de su colección, estaban completamente dedicadas a construir un público. "No basta -afirma Traba- con que los artistas de un país nuevo como Colombia se esfuercen por alcanzar un estilo, unas formas estéticas valederas; es preciso también que exista un público capaz de recibirlas, comprenderlas y valorarlas. El Museo de Arte Moderno de Bogotá, de la Universidad Nacional se considera ahora, en su nuevo edificio, con plena capacidad para adelantar tal empresa". ${ }^{0}$

A tres años de la iniciación de las actividades públicas del Museo, Marta Traba lo presentó como una institución no solo pertinente en términos de la construcción de un canon modernista, sino principalmente en relación con la formación de un nuevo público para las artes plásticas de la ciudad y el país. Este último es, sin duda, el principal pivote de la argumentación de todo el documento. Traba afirma:

Al integrarse con la Universidad Nacional, el Museo de Arte Moderno de Bogotá se propuso reforzar el carácter didáctico, apoyándose sobre el volumen aproximado de 12.000 estudiantes con que cuenta la Universidad. No se trata, sin embargo, de desvincular el Museo de Arte Moderno de la ciudadanía de Bogotá, sino, por el contrario, de conseguir que el público encuentre, en un edificio de la Universidad, un centro de cultura lo suficientemente poderoso para irradiar su influencia sobre toda la población. ${ }^{51}$

Visto en perspectiva, el ambicioso programa museológico inicialmente propuesto por las directivas del museo, ${ }^{52}$ con Marta Traba a la cabeza, estableció un espacio narrativo en el que la médula de la legitimación de su presencia en el ámbito cultural nacional, además de establecer un panorama continental de las artes plásticas dentro de la esfera del modernismo dominante en aquel entonces, y de empezar a configurar las bases de la canonización de los artistas modernistas a través de la colección del mismo, se volcó sobre uno de los objetivos que la misma Traba se había propuesto con su actividad crítica: la educación del público. ${ }^{53}$ Una y otra vez, desde que empezó a publicar sus columnas en los diferentes periódicos y revistas de la

50. Ibíd.

51. Ibíd., 1.

52. Según el mencionado catálogo, las directivas del Museo eran: Marta Traba, directora; Eugenio Barney-Cabrera, presidente de la Junta Directiva; Dicken Castro, vicepresidente; Germán Rubiano Caballero, Gloria Valencia Diago, Inés Torres de Quintero, Gloria Valencia de Castaño y Elena Piñeros de Angulo, vocales; Ana Bejarano de Uribe, secretaria; y Rosario Quintero, administradora y tesorera.

53. Giraldo, Marta Traba: crítica..., 109 y ss. 


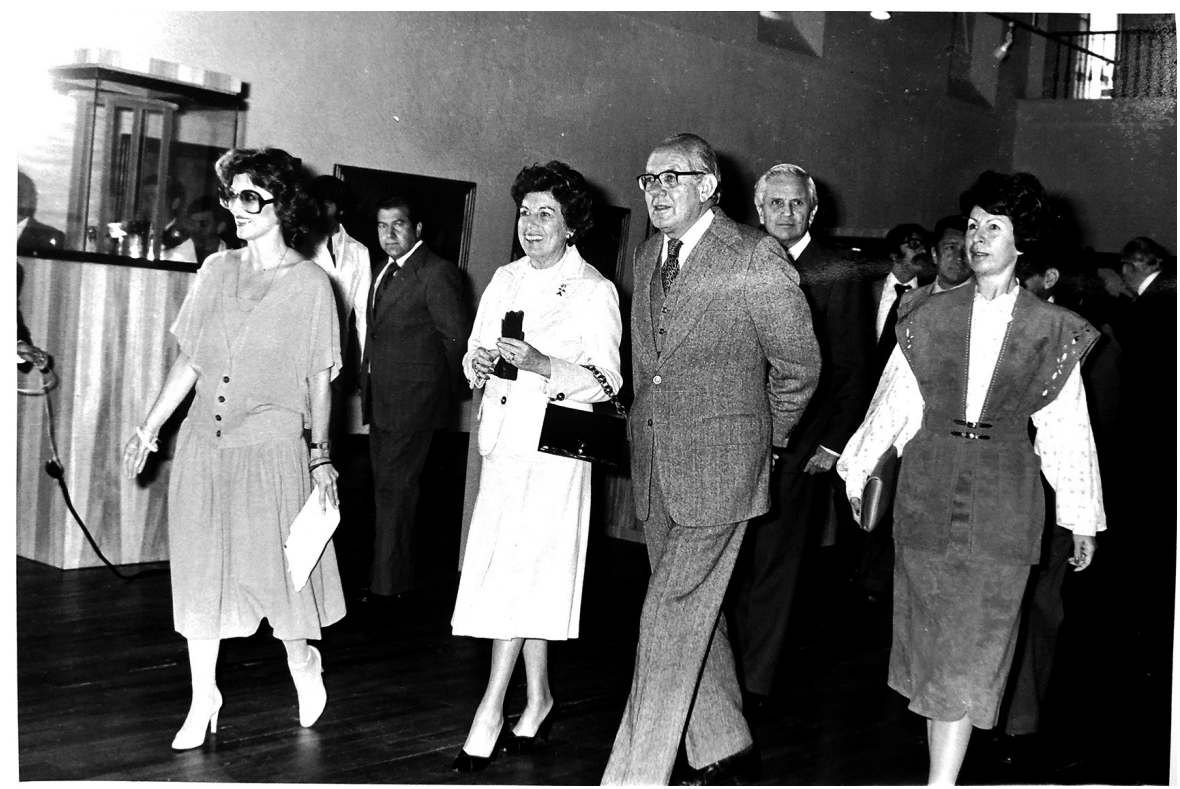

Figura 6. Inauguración de la renovación arquitectónica y curatorial del Museo Nacional de Colombia. De izquierda a derecha: Gloria Zea, directora del Instituto Colombiano de Cultura; Cecilia Caballero de López, primera dama de la nación; Alfonso López Michelsen, presidente de la República; y Emma Araújo de Vallejo, directora del Museo Nacional de Colombia. Atrás, entre López Michelsen y Araújo de Vallejo, Dicken Castro, arquitecto director del proyecto de intervención arquitectónica de la sede del Museo Nacional de Colombia. Anónimo, agosto de 1978. Archivo Histórico de la Universidad Nacional de Colombia, Fondo Emma Araújo de Vallejo.

capital, ella había señalado repetidamente que una de las principales labores de la crítica de arte era la interlocución con el público. Precisamente sobre este tema en particular, Traba había afirmado en 1961:

la crítica latinoamericana, al contrario de la europea, está obligada a ser pedagógica. Suponiendo que el público sabe de qué se trata, el crítico europeo puede darse el lujo de no enseñar. El latinoamericano debe insistir, golpear en algunas ideas muy simples, esclarecer confusiones, separar incesantemente, aun cuando se caiga en el simplismo profesoral, lo válido de lo inválido. La crítica debe prestar un servicio, caer un poco en la zona antipática, peligrosísima pero inevitable, de la "misión cultural". La forma como se cumple este objetivo no puede tener dos interpretaciones, a pesar de lo que aleguen los artistas, sobre todo los damnificados. Es preciso que sea drástica, que no admita concesiones, que no sienta misericordia ante las vocaciones erradas o inútiles. En Europa si alguien ensalza reiteradamente un mal pintor o un mal escultor no pasa nada (salvo que dicho pintor sea lo suficientemente hábil para esconder por un tiempo su mediocridad 
y que algún "marchand" lo sostenga). Entre nosotros todo mal artistas ensalzado llega a genio. El peligro es enorme. Por eso es tan necesario ir contra los fraudes artísticos, como a favor de los artistas verdaderos: no es posible quedar callado. ${ }^{54}$

\section{A Modo De CONCLUSIÓN}

A riesgo de simplificar de forma pedestre el proyecto museológico de Traba, se podría afirmar que su principal objetivo era la comunicación de su valoración de la obra de arte y de las trayectorias de los artistas dentro del paradigma del modernismo. Ese fue el eje del proyecto de la institución que ella dirigió entre 1962-1967; y, en este sentido, el horizonte último de su trabajo debía traducirse en la configuración de un canon modernista. Tareas que terminarán de completar y consolidar sus estudiantes y amigas a lo largo de las siguientes décadas, siguiendo la clave modernista que Traba había desarrollado a finales de la década de los cincuenta y que para el principio de los setenta ella misma había abandonado.

Baste señalar, como ejemplos paradigmáticos, las trayectorias profesionales de Emma Araújo de Vallejo y Beatriz González (1938). Ellas dos son agentes clave del proceso de institucionalización del legado de Marta Traba al promover su particular visión de la modernidad artística que la colomboargentina desarrolló desde su llegada al país, al menos hasta principios de los años sesenta: las dos fueron estudiantes suyas en la Universidad de los Andes, ambas tuvieron una decidida injerencia en la consolidación de proyectos museológicos en clave modernista a lo largo de las décadas de los años sesenta, setenta y ochenta (Museo Nacional de Colombia, Museo de Arte Moderno y Museo de Arte del Banco de la República), y también estuvieron profundamente comprometidas en la edición y publicación de la antología de textos críticos con autoría de Traba que el Museo de Arte Moderno publicó en 1984, con la que se consolidó la sistematización de su trabajo a un año de su muerte. ${ }^{55}$

Sin la menor duda, González de Ripoll, por su cuádruple adscripción como artista, crítica, curadora e historiadora del arte dentro del campo artístico colombiano, no solo es la más connotada de todas las estudiantes de Marta Traba, sino posiblemente la que más injerencia ha tenido dentro de la perpetuación del "trabismo" en el ámbito colombiano. Al ocupar posiciones análogas a las que configuró Marta Traba dentro del campo artístico colombiano, no solo se la ha visto como heredera legítima de su legado crítico, sino

54. Marta Traba, “La crítica criticada”, Estampa, n. ${ }^{\circ} 1130$ (1961): 6.

55. Véase Emma Araújo de Vallejo, ed., Marta Traba (Bogotá: Museo de Arte Moderno / Planeta, 1984). 


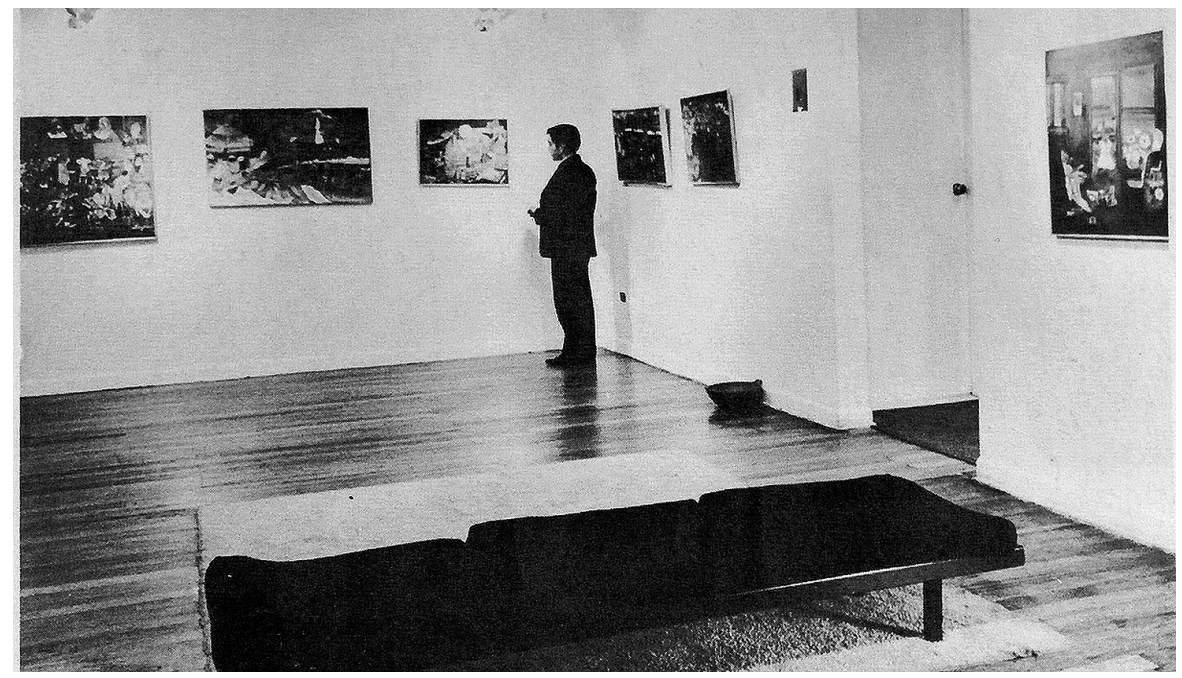

Figura 7. Aspecto de una de las salas de exposición del Museo de Arte Moderno de Bogotá en el campus de la Universidad Nacional de Colombia. Foto: EGAR. Tomado de Traba (1966). (Archivo Ruth Acuña).

que, incluso, se la ha caracterizado de formas muy semejantes. No es casual que, al igual que a Marta Traba, a González de Ripoll también se le haya denominado la "papisa del arte colombiano". Recuérdese cómo Pablo Batelli, uno de los autores más activos dentro de los sitios de discusión sobre arte colombiano surgidos en la web, se refería a ella en 2009:

Como si fuera en el café, debo forzosamente coincidir en el papel nefasto de Beatriz González como nueva sacerdotisa (o papisa) del arte nacional, heredera de los "hábitos" modernistas de Marta Traba (los que son, en efecto, necesarios para la perpetuación de la ilusión de la necesidad del arte moderno y postmoderno). [...] Beatriz González no habría sido nunca un factor importante del arte nacional si: no hubiera sido partícipe de esa burguesía de izquierda acomodada paternalista y: si no hubiera sido parte de los beneficios del programa de arte moderno internacional con el que Marta Traba se instauró como crítica en un territorio propicio que requería la "instauración" de sus "propicios". 56

Por otra parte, entre todas las estudiantes de Marta Traba, Beatriz González es quien ha producido el mayor número de artículos sobre el legado

56. Pablo Batelli, “Comentario a 'Terror en la 26" ", 15 de septiembre de 2009, http:/ / contraesfera.wordpress.com/2009/08/31/terror-en-la-26/. 
crítico y museológico de la argentino-colombiana, ${ }^{57}$ y es la autoridad indiscutidamente referenciada por la mayoría de los estudios que se han hecho sobre la misma dentro y fuera del campo de las artes plásticas. ${ }^{58}$

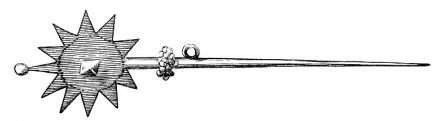

\section{BibliografíA}

Acuña Prieto, Ruth Nohemí. "El papel periódico ilustrado y la génesis de la configuración del campo artístico en Colombia". Tesis de maestría. Universidad Nacional de Colombia, sede Bogotá. 2002.

Araújo de Vallejo, Emma, editora. Marta Traba. Bogotá: Museo de Arte Moderno de Bogotá / Planeta, 1984.

Armatto, Alessandro. "La 'primera piedra': José Gómez Sicre y la fundación de los museos interamericanos de arte moderno de Cartagena y Barranquilla". Revista Brasileira do Caribe 12, n. ${ }^{\circ} 4$ (enero-junio 2012): 381-404.

Barney-Cabrera, Eugenio, director. Historia del arte colombiano. Bogotá: Salvat, 1975.

Batelli, Pablo. "Comentario a 'Terror en la 26' ", 15 de septiembre de 2009. http:/ / contraesfera.wordpress.com/2009/08/31/terror-en-la-26/.

Bazzano-Nelson, Florencia. "Cambios de margen: las teorías estéticas de Marta Traba". En Marta Traba, Dos décadas vulnerables en las artes plásticas latinoamericanas 1950-1970. Buenos Aires: Siglo XXI Editores, 2005.

. "Marta Traba y México: Una historia de encuentros y desencuentros". En El programa cultural y político de Marta Traba: Relecturas, editado por Gustavo Zalamea. Bogotá: Universidad Nacional de Colombia, Facultad de Artes, 2018. . Theory in Context: Marta Traba's Art-Critical Writings and Colombia, 19451959". Tesis de doctorado. University of New Mexico, Albuquerque. 2000.

57. Véase Beatriz González, "Marta Traba”. En Santiago Castro-Gómez et al., Pensamiento colombiano siglo XX (Bogotá: Pontificia Universidad Javeriana, 2007), y Beatriz González, "Marta Traba y la crítica de una década". En El programa cultural y político de Marta Traba. Relecturas, ed. por Gustavo Zalamea (Bogotá: Facultad de Artes / Universidad Nacional de Colombia, 2008), 69 y ss.

58. Véase Florencia Bazzano-Nelson, “Theory in Context: Marta Traba's Art-Critical Writings and Colombia, 1945-1959" (tesis doctoral, University of New Mexico, Albuquerque, 2000); "Cambios de margen: las teorías estéticas de Marta Traba". En Marta Traba, Dos décadas vulnerables en las artes plásticas latinoamericanas 1950-1970 (Buenos Aires: Siglo XXI Editores, 2005), 9 y ss.; "Marta Traba y México: una historia de encuentros y desencuentros". En El programa cultural y político..., 199 y ss.; Giraldo, Marta Traba: crítica...; y, Álvaro Tirado Mejía, Los años sesenta. Una revolución en la cultura (Bogotá: Debate, 2014). 
Boltanski, Luc. "Usos débiles y fuertes del habitus". En Trabajar con Bourdieu, editado por Pierre Encrevé y Rose-Marie Lagrave, 167-176. Bogotá: Universidad Externado de Colombia, 2005.

Bourdieu, Pierre. Creencia artística y bienes simbólicos. Elementos para una sociología de la cultura. Buenos Aires: Aurelia Rivera, 2003.

. Las reglas del arte. Génesis y estructura del campo literario. Barcelona: Anagrama, 1995.

. Meditaciones pascalianas. Barcelona: Anagrama, 1999.

- Sociología y cultura. México: Grijalbo / Consejo Nacional para la Cultura y las Artes, 1990.

Cockcroft, Eva. "Abstract Expressionism, Weapon of the Cold War". Artforum, n. ${ }^{\circ} 10$ (junio 1974): 39-41.

Duncan, Carol. Rituales de civilización. Murcia: Nausícaä, 2007.

Elderfield, John, et al., Imagining the Future of the Museum of Modern Art. Nueva York: Museum of Modern Art of New York, 1998.

França Lourenço, Maria Cecília. Museus Acolhem o Moderno. São Paulo: Editora da Universidade de São Paulo, EDUSP, 1999.

Garay Celeita, Alejandro. "El campo artístico colombiano en el Salón de 1910". Historia Crítica, n. ${ }^{\circ} 32$ (julio-diciembre 2006): 302-333.

Giraldo, Efrén. Marta Traba: crítica del arte latinoamericano. Medellín: La Carreta / Universidad de Antioquia, 2007.

González, Beatriz. Arte internacional. Colección del Banco de la República. Bogotá: Villegas Editores, 2009.

"Marta Traba". En Santiago Castro-Gómez et al., Pensamiento colombiano siglo XX. Bogotá: Pontificia Universidad Javeriana, 2007.

. "Marta Traba y la crítica de una década". En El programa cultural y político de Marta Traba. Relecturas, editado por Gustavo Zalamea. Bogotá: Facultad de Artes / Universidad Nacional de Colombia, 2008.

González Gallego, Julián Andrés. “El Museo La Tertulia: 50 años de frente a la ciudad". Tesis de licenciatura. Universidad del Valle. 2006.

Gordon Kantor, Sybil. Alfred H. Barr Jr. and the Intellectual Origins of the Museum of Modern Art. Boston: MIT, 2002.

Giunta, Andrea. Vanguardia, internacionalismo y política. Arte argentino en los años sesenta. Buenos Aires: Paidós, 2001.

y Giunta, Andrea, y Laura Malosetti Costa, compiladoras. Arte de posguerra. Jorge Romero Brest y la revista Ver y Estimar. Buenos Aries: Paidós, 2005.

Guilbaut, Serge. De cómo Nueva York se robó la idea de arte moderno. Madrid: Mondadori, 1990.

Gutiérrez, Alicia B. "A modo de introducción. Los conceptos centrales en la sociología de la cultura de Pierre Bourdieu". En Pierre Bourdieu, El sentido social del gusto. Elementos para una sociología de la cultura. Buenos Aires: Siglo XXI Editores, 2010.

Jaramillo Jiménez, Carmen María. “Una mirada a los orígenes del campo de la crítica de arte en Colombia". Artes. La Revista 4, n. 7 (enero-junio 2004): 3-38.

Jaramillo Jiménez, Jaime Eduardo. “Protocampo y campo intelectual en Latinoamérica: los intelectuales en la periferia". Inédito, 2003. 
- Universidad, politica y cultura: la rectoría de Gerardo Molina en la Universidad Nacional de Colombia -1944-1948-. Bogotá: Universidad Nacional de Colombia, 2007.

Kozloff, Max. "American Painting During the Cold War". Artforum, n. 9 (mayo 1973): 43-54.

Londoño Vélez, Santiago. Arte colombiano 3.500 años de historia. Colección Banco de la República. Bogotá: Villegas Editores, 2001.

López Rosas, William Alfonso. “Apuntes para una historia del Museo de Arte Moderno de Bogotá: la autonomización del campo cultural y la construcción de la hegemonía del arte modernista (1949-1970)". Cuadernos de Música, Artes Visuales y Artes Escénicas 10, n. 2 (julio-diciembre 2015): 15-35.

. Emma Araújo de Vallejo. Su trabajo por el arte, la memoria, la educación y los museos. Bogotá: Universidad Nacional de Colombia, 2015.

. “La crítica de arte en el Salón de 1899: una aproximación a los procesos de configuración del campo artístico en Colombia". Tesis de maestría. Universidad Nacional de Colombia. 2005.

. Miguel Díaz Vargas: Una modernidad invisible. Bogotá: Fundación Gilberto Alzate Avendaño, 2007.

. "Museos, patrimonio cultural y mecenazgo: los límites conceptuales de la financiación de las instituciones de la memoria en Colombia". Revista Colombiana de Antropología 46, n. ${ }^{\circ} 1$ (enero-junio 2010): 87-114.

Maldonado Copello, Alberto, y Yolanda López Correal. Estado del arte del área de artes plásticas en Bogotá D. C. Bogotá: Instituto Distrital de Cultura y Turismo / Alcaldía Mayor de Bogotá, 2006.

Medina, Álvaro. Procesos del arte en Colombia. Bogotá: Instituto Colombiano de Cultura, 1978.

Mejía de López, Ángela. La escultura en la Colección Pizano. Bogotá: Museo de Arte / Universidad Nacional de Colombia, 1984.

Mesa Mendieta, Alexandra. "Museo de Arte Moderno de Bogotá: primera pincelada 1963-1965". Quintana, n. ${ }^{\circ} 15$ (2016): 203-222.

Molina Londoño, Luis Fernando. Historia de una empresa cultural. Biblioteca Luis Ángel Arango (1957-2007). Bogotá: Banco de la República, 2013.

Moreno Moya, Nadia. Arte y juventud. El Salón ESSO de artistas jóvenes en Colombia. Bogotá: IDARTES, 2013.

Motta, Renata. "Museos de arte en Brasil: entre lo moderno y lo contemporáneo". En El museo en escena. Política y cultura en América Latina, compilado por Américo Castillo, 185-205. Buenos Aries: Paidós / Fundación TyPA, 2010.

O'Doherty, Brian. Inside the White Cube. The Ideology of the Gallery Space. Santa Mónica: The Lapis Press, 1986.

Padilla Peñuela, Christian. La llamada de la tierra. El nacionalismo en la escultura colombiana. Bogotá: Fundación Gilberto Alzate Avendaño / Alcaldía Mayor de Bogotá, 2008.

Quintero Montero, María del Pilar. “El Museo de Arte Moderno de Bogotá: formación y programa cultural entre 1963 y 1965. Trabajando por crear un espacio para el arte moderno". Tesis de maestría. Universidad de Bogotá Jorge Tadeo Lozano. 2015. 
Ramírez Botero, Isabel Cristina. Ampliando el mapa. Nuevas aproximaciones a los procesos locales y regionales en la historia del arte moderno en Colombia. El caso de Barranquilla y Cartagena. Bogotá: Instituto Distrital de las Artes de Bogotá / Universidad Jorge Tadeo Lozano, 2011.

- El arte en Cartagena a través de la colección del Banco de la República. Cartagena: Banco de la República, 2010.

Rodríguez, Marta. El dibujo en Colombia. Una mirada a la colección del Museo de Arte de la Universidad Nacional de Colombia. Bogotá: Museo de Arte / Universidad Nacional de Colombia, 2001.

- La abstracción en Colombia vista desde la colección del Museo de Arte de la Universidad Nacional - Obra bidimensional. Bogotá: Museo de Arte / Universidad Nacional de Colombia, 1998.

Rosas Mantecón, Ana, y Graciela Schmilchuk. “Del mito de las raíces a la ilusión de la modernidad internacional en México". En El museo en escena. Política y cultura en América Latina, compilado por Américo Castillo, 145-166. Buenos Aries: Paidós / Fundación TyPA, 2010.

Sánchez Gómez, Gonzalo, y María Emma Wills Obregón. Museo, memoria y nación. Misión de los museos nacionales para los ciudadanos del futuro. Memorias del Simposio Internacional y del IV Cátedra Anual de Historia Ernesto Restrepo Tirado. Bogotá: Museo Nacional de Colombia, 1999.

Segura, Marta, editora. La arqueología, la etnografía, la historia y el arte en el Museo. Memorias de los coloquios nacionales. Bogotá: Museo Nacional de Colombia, 2001.

Serna Lancheros, Julián Camilo. El valor del arte: una historia de las primeras galerías de arte en Colombia (1948-1957). Bogotá: Universidad EAN, 2011.

Serrano, Eduardo. El Museo de Arte Moderno de Bogotá. Recuento de un esfuerzo conjunto. Bogotá: Museo de Arte Moderno de Bogotá, 1979.

Silva, Renán. República liberal, intelectuales y cultura popular. Medellín: La Carreta, 2005.

Suárez Segura, Sylvia Juliana. Salón de arte moderno 1957: 50 años de arte en la Biblioteca Luis Ángel Arango. Bogotá: Banco de la República, 2007.

Suescún Pozas, María del Carmen. "Los museos de arte moderno y la reconfiguración de lo local a través de lo foráneo: transformando a Colombia en un país 'abierto' ". Memoria y Sociedad 3, n. ${ }^{\circ} 6$ (1999): 135-142.

Tirado Mejía, Álvaro. Los años sesenta. Una revolución en la cultura. Bogotá: Debate, 2014.

Traba, Marta. El Museo de Arte Moderno y la Universidad Nacional. Bogotá: Museo de Arte Moderno / Universidad Nacional de Colombia, 1966.

. Historia abierta del arte colombiano. Cali: Museo de Arte Moderno La Tertulia, 1974.

“La crítica criticada”. Estampa, n. ${ }^{\circ} 130$ (1961).

Uribe de Urdinola, Maritza, y Miguel González. Museo de Arte Moderno La Tertulia. Cali: Museo de Arte Moderno La Tertulia, 1996.

Urrego, Miguel Ángel. Intelectuales, Estado y Nación en Colombia. De la guerra de los Mil Días a la Constitución de 1991. Bogotá: Siglo del Hombre / Universidad Central, 2002.

VV. AA. Compendio de políticas culturales. Bogotá: Ministerio de Cultura, 2010. 
. La contemporaneidad en Colombia - Museo de Arte Contemporáneo 40 años. Bogotá: Museo de Arte Contemporáneo / Corporación Universitaria UNIMINUTO, 2006.

- Museo de Arte Moderno de Cartagena de Indias. Cartagena: Asociación de Amigos del Museo de Arte Moderno de Cartagena de Indias / Villegas Editores, 2009.

Verlichak, Victoria. Marta Traba. Una terquedad furibunda. Buenos Aires: Universidad Nacional de Tres de Febrero / Fundación PROA, 2001.

Wallach, Allan. Exhibiting Contradiction. Essays on the Art Museum in the United States. Boston: The University of Massachusetts Press, 1998.

Zea, Gloria. El Museo de Arte Moderno de Bogotá. Una experiencia singular. Bogotá: Museo de Arte Moderno de Bogotá / El Sello Editorial, 1994. 